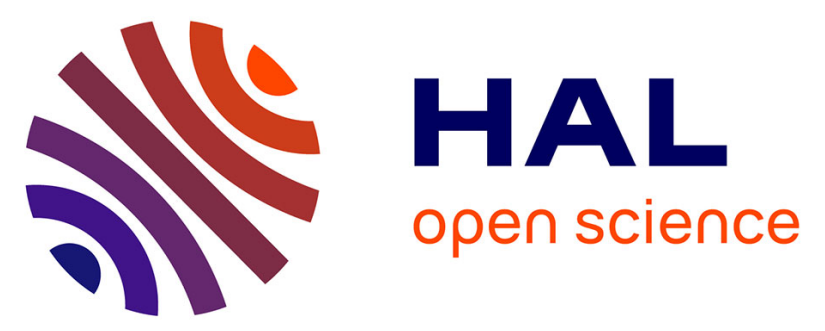

\title{
Early Transition Metal Nano-carbides and Nanohydrides from Solid-State Metathesis initiated at Room Temperature
}

\author{
Rémi F André, Florian d'Accriscio, Alexy P Freitas, Guillaume Crochet, \\ Corinne Bouillet, Mounib Bahri, Ovidiu Ersen, Clément Sanchez, Sophie \\ Carenco
}

\section{To cite this version:}

Rémi F André, Florian d'Accriscio, Alexy P Freitas, Guillaume Crochet, Corinne Bouillet, et al.. Early Transition Metal Nano-carbides and Nanohydrides from Solid-State Metathesis initiated at Room Temperature. Green Chemistry, 2021, 10.1039/D1GC01097B . hal-03329765

\section{HAL Id: hal-03329765 https://hal.sorbonne-universite.fr/hal-03329765}

Submitted on 31 Aug 2021

HAL is a multi-disciplinary open access archive for the deposit and dissemination of scientific research documents, whether they are published or not. The documents may come from teaching and research institutions in France or abroad, or from public or private research centers.
L'archive ouverte pluridisciplinaire HAL, est destinée au dépôt et à la diffusion de documents scientifiques de niveau recherche, publiés ou non, émanant des établissements d'enseignement et de recherche français ou étrangers, des laboratoires publics ou privés. 


\section{Early Transition Metal Nano-carbides and Nano-}

\section{hydrides from Solid-State Metathesis initiated at Room \\ Temperature}

Rémi F. André, ${ }^{1}$ Florian D'Accriscio, ${ }^{1}$ Alexy P. Freitas, ${ }^{1}$ Guillaume Crochet, ${ }^{1}$ Corinne Bouillet, ${ }^{2}$ Mounib Bahri, ${ }^{2}$ Ovidiu Ersen, ${ }^{2}$ Clément Sanchez, ${ }^{1}$ Sophie Carenco, ${ }^{1, *}$

${ }^{1}$ Sorbonne Université, CNRS, Collège de France, Laboratoire de Chimie de la Matière Condensée de Paris (LCMCP), 4 place Jussieu, 75005 Paris, France

${ }^{2}$ Institut de Physique et Chimie des Matériaux de Strasbourg (IPCMS), UMR 7504 CNRSUniversité de Strasbourg, 23 rue du Loess, 67034 Strasbourg Cedex 2, France

*Corresponding author. E-mail: sophie.carenco@ sorbonne-universite.fr 


\begin{abstract}
:
Transition metal carbides (TMCs) have attracted great interest due to their mechanical and catalytic properties but their syntheses generally require energy-consuming processes with temperatures above $800{ }^{\circ} \mathrm{C}$. We report here a solid-state metathesis reaction between metal chlorides $\left(\mathrm{ZrCl}_{4}, \mathrm{NbCl}_{5}, \mathrm{MoCl}_{3}, \mathrm{MoCl}_{5}, \mathrm{HfCl}_{4}, \mathrm{TaCl}_{5}, \mathrm{WCl}_{6}\right)$ and potassium dispersed in carbon (graphite or acetylene black). The reaction is initiated at room temperature or with gentle heating below $75^{\circ} \mathrm{C}$. Within seconds, it produces carbon-supported carbide or metallic nanoparticles of diameter below $50 \mathrm{~nm}$. The phase speciation depends on the metal and different process parameters. In some cases $\left(\mathrm{ZrCl}_{4}, \mathrm{NbCl}_{5}, \mathrm{HfCl}_{4}, \mathrm{TaCl}_{5}\right)$, the metal is further converted into a hydride upon neutralization of the reaction crude with ethanol. The products were characterized by powder X-ray diffraction (PXRD) and Transmission Electron Microscopy (TEM). Based on thermodynamic and kinetic considerations, we propose a mechanism explaining the coexistence of several phases (metal, carbide, hydride) and their occurrence at each step of the reaction.
\end{abstract}

Keywords: solid-state metathesis, self-propagating high temperature synthesis, nanoparticle synthesis, metal carbides, metal hydrides. 


\section{Introduction}

Transition metal carbides (TMCs) are interstitial alloys formed by the incorporation of carbon atoms into the close-packed lattices of transition metals (TM). TMCs are materials of high interest considering their excellent mechanical stability (high melting point and hardness) and chemical resistance to acids and bases, making them suitable candidates for cutting tools, crucibles or abrasives. ${ }^{[1]}$ Due to their catalytic activity similar to Pt-group metals, molybdenum carbide $\left(\mathrm{Mo}_{2} \mathrm{C}\right)$ and tungsten carbides $\left(\mathrm{WC}\right.$ and $\left.\mathrm{W}_{2} \mathrm{C}\right)$ are also studied as substitutes of rare and expensive metals for catalytic applications, in particular electrochemical $^{[2]}$ and hydrogenation reactions. ${ }^{[3,4]}$ Most of the TMC syntheses imply an extended time of reaction (up to one week) at elevated temperatures $\left(>800^{\circ} \mathrm{C}\right)$ between the metal precursor and a carbon source such as graphite, a polymer or light hydrocarbons. ${ }^{[5]}$ To limit the oxidation of the material, the reaction is usually conducted under a reductive or an inert atmosphere. The high temperatures and the long reaction times are critical for these syntheses to overcome the solid-state diffusion barrier of carbon into metal. They represent a costly step in terms of energy.

Energy-saving alternative pathways were established during the past decades for the production of ceramics and refractive materials, and are now used by manufacturers. ${ }^{[6-8]}$ For instance, Self-propagation High-temperature Syntheses (SHS) were extensively studied by Merzhanov and others in the $1980 \mathrm{~s} .{ }^{[8]}$ In an SHS, the reaction produces enough heat so that the solid-state reaction is self-sustained at high temperature, without need for external heating. Highly exothermic reactions are needed to enter in this regime. Although the reaction is initiated at low temperatures, the reaction temperature itself can go above $1300{ }^{\circ} \mathrm{C}$ within a second, leading to highly crystalline products, followed by a rapid cooling. SHS were initially used on compressed powder mixtures, yielding bulk TMCs among other compounds, and were then extended to TMC nanoparticles (NPs). ${ }^{[9,10]}$ 
Transition metal halide salts have been extensively used as the metallic source due to their simplicity and in order to obtain highly exothermic reactions. When these particular reagents are used, SHS reactions are called Solid-State Metathesis (SSM) reactions. They permit the formation of carbides and other refractive compounds containing a light element, such as carbides, nitrides, silicides or phosphides. SSM reactions were studied by Kaner, Parkin et al. ${ }^{[7,11]}$ When using a metal chloride, a reducing agent is needed to reduce the metallic center. It is usually a derivative of an alkaline or earth-alkaline metal in combination with the light element to be inserted. The heat released by the reaction of the two solid partners allows an exchange of atoms between the two compounds to yield the targeted phase, hence its name "metathesis". ${ }^{[12]}$ Various works report the use of $\mathrm{MgB}_{2}$ for borides, ${ }^{[13]} \mathrm{CaC}_{2}$, $\mathrm{SrC}_{2}, \mathrm{Al}_{4} \mathrm{C}_{3}$ for carbides, ${ }^{[9,10]} \mathrm{Li}_{3} \mathrm{~N}, \mathrm{NaN}_{3}$ for nitrides, ${ }^{[14-16]}, \mathrm{Mg}_{2} \mathrm{Si}, \mathrm{CaSi}_{2}$ for silicides, ${ }^{[17]}$ $\mathrm{Na}_{3} \mathrm{P}$ for phosphides, ${ }^{[18]} \mathrm{Na}_{2} \mathrm{~S}$ for sulfides,${ }^{[19]}$ etc. The metal chloride $\left(\mathrm{MCl}_{x}\right)$ and the reducing agent are introduced in stoichiometric proportions as regard to the electron transfer, i.e. $x$ electrons provided by $x$ alkaline metal atoms of $x / 2$ earth-alkaline metal atoms for one $\mathrm{MCl}_{x}$. In some cases, the excess of light element $(\mathrm{B}, \mathrm{C}, \mathrm{N}, \mathrm{Si}, \mathrm{S}$ or $\mathrm{P})$ is recovered under its elemental form as a byproduct of the reaction, e.g. graphitic carbon or $\mathrm{N}_{2}$. The reaction is driven by the high lattice energy of the coproduced chloride salt ( $\mathrm{LiCl}, \mathrm{NaCl}, \mathrm{KCl}, \mathrm{CaCl}_{2}$, $\left.\mathrm{AlCl}_{3}\right) \cdot{ }^{[9,10,16,19,20]}$ When the precursor is a TM oxide, the reaction is called a Modified SolidState Metathesis (MSSM) and is driven by the formation of the alkaline oxide, such as $\mathrm{Li}_{2} \mathrm{O}$, $\mathrm{CaO}$ or $\mathrm{SrO} .{ }^{[15,21]}$ In both cases, SSM and MSSM, the reaction enthalpy is largely negative (500-2000 kJ/mol per atom of metal), hence the high exothermicity and reaction temperature. The reaction is either initiated by mixing or grinding of the reagents for the more reactive mixtures, or by gradually heating the powder mixture up to the point the partners suddenly react: this temperature is called the ignition temperature $T_{i g}$. 
Following this route, our group recently developed an expeditious way to access finely divided NPs dispersed on a carbon support via an SSM reaction initiated under ambient conditions between a metal chloride $\left(\mathrm{MCl}_{x}\right)$ and metallic potassium dispersed in carbon, $\mathrm{KC}_{8}$ or $\mathrm{KC}_{4} \cdot{ }^{[20]}$ Potassium-graphite $\left(\mathrm{KC}_{8}\right)$ is an intercalation compound of potassium atoms in graphite, it was first reported in the $1920 \mathrm{~s}^{[22]}$ and was then widely used as a reagent or a catalyst considering its excellent properties as a reducing agent. ${ }^{[23,24]}$ Potassium in acetylene black $\left(\mathrm{KC}_{4}\right)$ is not an intercalation compound but is obtained by impregnation of liquid potassium into $50 \mathrm{~nm}$ large spheres of acetylene black. The potassium-containing compound $\left(\mathrm{KC}_{8}\right.$ or $\left.\mathrm{KC}_{4}\right)$ reduces the metal chloride to form $\mathrm{KCl}$ along with metal( $(0)$ or carbide NPs. The $\mathrm{KC}_{4} / \mathrm{KC}_{8}$ process presents many advantages in terms of green chemistry: no solvent, no high or prolonged heating, non-toxic reagents and innocuous wastes. Moreover, it is versatile as it was applied to numerous early transition metals ( $\mathrm{Ti}, \mathrm{V}, \mathrm{Mo}$ and $\mathrm{W}$ in the initial work, $\mathrm{Zr}, \mathrm{Nb}$, Mo, Hf, Ta and $\mathrm{W}$ in the present one).

The influence of the different process parameters was however not studied so far and is the object of the present work, which also provides a rationalization of the results in the framework of SSM reactions. The present study also investigates the formation of carbides with additional elements: $\mathrm{Ta}, \mathrm{Zr}, \mathrm{Nb}$ and $\mathrm{Hf}$. While exploring different reaction conditions, a synthetic path to metal hydride nanoparticles was found by serendipity. In this article, we exploit the specificities of $\mathrm{KC}_{4}$ and $\mathrm{KC}_{8}$, in particular the low ignition points, to tune the phase speciation in the product. We first discuss the nature of the products of the reaction performed with metals of the Group IV ( $\mathrm{Zr}$, Hf), of the Group V (Nb, Ta) and of the Group VI (Mo, W). The products were analyzed by a combination of spectroscopies and microscopies. We put these results in light of thermodynamic considerations based on the enthalpies of reaction. We demonstrate that the reaction is not under thermodynamic control. Then, we explore the influence of different process parameters (nature of carbon support, precursor 
granularity, gas phase, scale...) on the metal speciation by Powder X-ray Diffraction (PXRD). Finally, we propose a mechanism for the NPs synthesis and subsequent modifications. 


\section{Results and discussions}

\subsection{Chemical trends}

Combustion reaction. The reaction is a solid-state combustion reaction where the reducing agent is potassium $(\mathrm{K})$, either dispersed in acetylene black at 0.25 equivalent (corresponding composition: $\left.\mathrm{KC}_{4}\right)$ or inserted in graphite $\left(\mathrm{KC}_{8}\right)$. The oxidant is a metal chloride of general formula $\mathrm{MCl}_{x}(\mathrm{M}=\mathrm{Zr}, \mathrm{Nb}, \mathrm{Mo}, \mathrm{Hf}, \mathrm{Ta}, \mathrm{W})$. In Eq. $1, \mathrm{MCl}_{x}$ and the reducing agent are introduced in stoichiometric proportions, i.e. one equivalent of $\mathrm{K}$ per electron to provide to the chloride for its full reduction. The oxidation number of the metal $\mathrm{M}$ is reduced to (0) to form NPs supported on carbon, with $\mathrm{KCl}$ salt and carbon as the main coproducts. Here, $[\mathrm{M}]$ denotes a species containing a metal(0), a metal carbide, a metal hydride or a metal oxide.

$$
\mathrm{MCl}_{x}+x \mathrm{KC}_{4} \text { or } 8 \rightarrow[\mathrm{M}]+x \mathrm{KCl}+\text { excess } \mathrm{C}
$$

Potassium is pyrophoric so the reaction must be conducted in the absence of dioxygen and water. The solid reagents are mixed by handshaking in a Schlenk tube under argon. Alternatively, the gas phase is changed for $\mathrm{N}_{2}$ or removed to perform the reaction under static vacuum, before shaking the Schlenk. Mixtures with metal chlorides of Group V and VI spontaneously ignite within seconds or minutes under vacuum while an initial activation with gentle heating (below $75^{\circ} \mathrm{C}$ ) is required for Group IV metals. Snapshots of the reactions performed with $\mathrm{ZrCl}_{4}$ and $\mathrm{KC}_{4}$ display an initiation point in the powder followed by a progression of the reaction front in the powder, at the speed of $c a .5 \mathrm{~cm} / \mathrm{s}$ (Fig. S1). Similar behaviors were observed with the other metals, thereby confirming the classification of the reaction as a Self-propagation High-temperature combustion Synthesis (SHS). In all cases but more particularly for reactions with $\mathrm{KC}_{4}$ under vacuum, a black particulate solid was spread over the walls of the reaction tube, due to the explosivity of the reaction. The traces of unreacted pyrophoric $\mathrm{KC}_{4}$ or $\mathrm{KC}_{8}$ were finally neutralized with ethanol, and the powder was 
washed with water to remove $\mathrm{KCl}$ and traces of unreacted metal chloride. Iridescences were observed on the glass vessel: they can be explained by the formation of a thin layer of a compound (probably metallic potassium or $\mathrm{KCl}$ ) which has been previously sublimed by the heat released by the reaction. During the washing step, the supernatants sometimes displayed characteristic colors of metal complexes (blue for $\mathrm{W}$, brown for Mo, grey for $\mathrm{Zr}, \mathrm{Nb}$, Hf and Ta), indicating that not all the reagents were consumed. The mass of the recovered powder was always of the order of that expected for a full reduction of the metal chloride.

Structural analysis. Figure 1 displays the Powder X-ray Diffraction patterns of the crystalline inorganic products of the reactions with $\mathrm{KC}_{4}$, performed under argon. All the metal chloride precursors used in this study, to the exception of $\mathrm{MoCl}_{3}$, are either soluble or hydrolyzed in water, therefore, the traces of unreacted precursor were not detected by PXRD in the final product. Despite the washing step, traces of sylvite $(\mathrm{KCl})$ appear on all the diffractograms and the diffraction peak at $28.3^{\circ}$ was used as a common calibration peak for the angle position $2 \theta$ of the detector. For the interpretation of diffractograms, although PXRD is not a quantitative method, we assumed the phases leading to the strongest diffraction peaks are the major crystalline ones. We worked under the assumptions that the phases identified in PXRD are representative of the sample, that there is only a limited amount of amorphous material and that the oxidation layer of the objects exposed to air is small enough to be neglected in a first approach. 

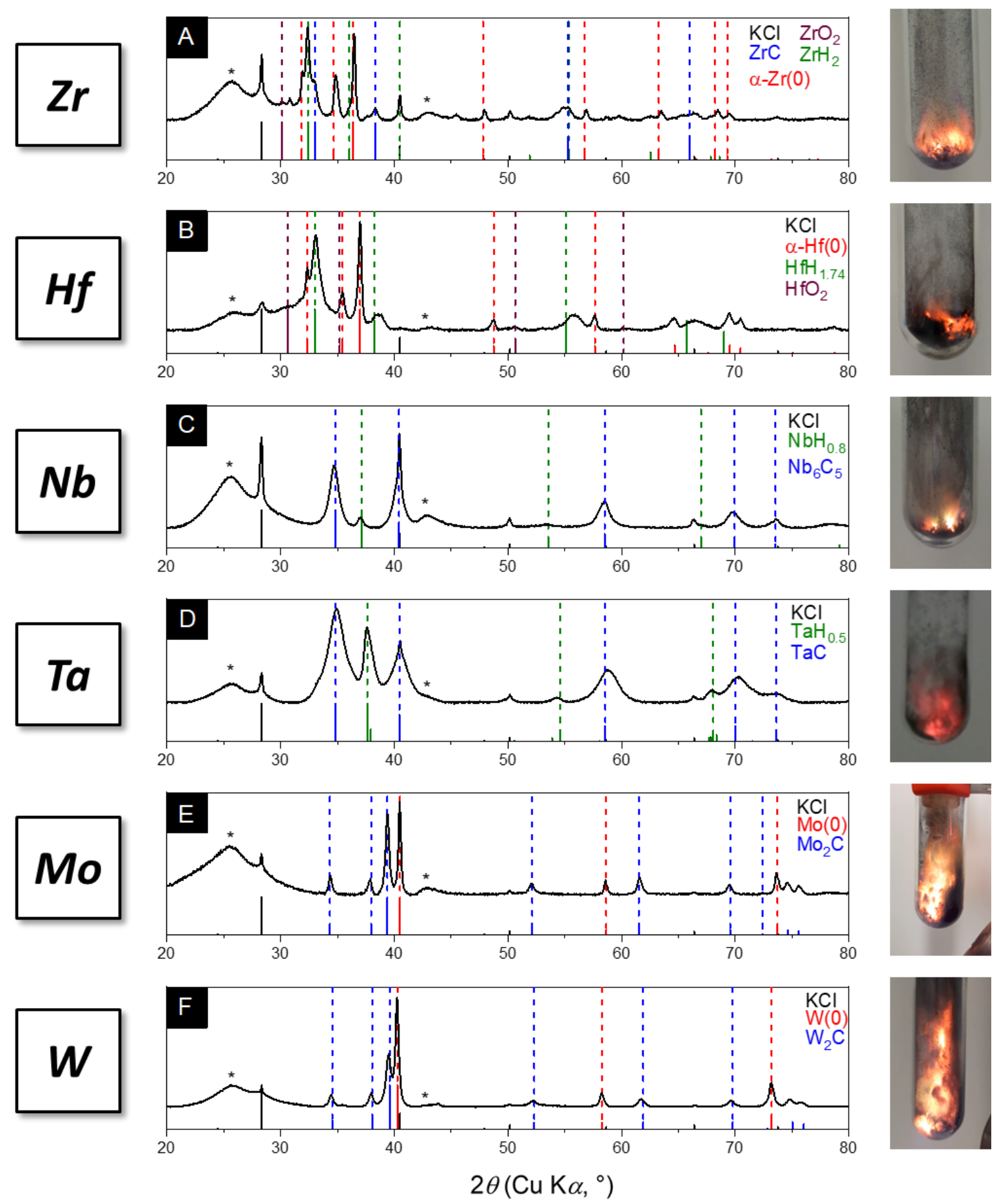

Figure 1. (Left) PXRD patterns of washed powders obtained by the reaction of $\mathrm{KC}_{4}$ and metal chlorides under Ar: (A) $\mathrm{ZrCl}_{4}$, (B) $\mathrm{HfCl}_{4}$, (C) $\mathrm{NbCl}_{5}$, (D) $\mathrm{TaCl}_{5}$, (E) $\mathrm{MoCl}_{5}$, (F) $\mathrm{WCl}_{6}$. Asterisks indicate the acetylene black peaks. (Right) Snapshots of the explosion observed in the corresponding reaction. 
Group IV metals. Metallic zirconium and hafnium can form a variety of phases but only $\alpha-\mathrm{Zr}$ and $\alpha-\mathrm{Hf}$ are detected here (Figure $1 \mathrm{~A}-\mathrm{B}$, peaks at respectively $36.4^{\circ}$ and $37.0^{\circ}$ indicated by red dashed lines). These phases are the low-temperature metallic phases: the phase transition toward the high-temperature ones $\alpha \rightarrow \beta$ occurs at respectively $862{ }^{\circ} \mathrm{C}$ and $1780{ }^{\circ} \mathrm{C}$ for $\operatorname{Zr}(0)$ and $\mathrm{Hf}(0) .{ }^{[25]}$ The other major species for these two reactions are the metal hydride (peaks at respectively $32.4^{\circ}$ and $33.0^{\circ}$, indicated by green dashed lines), attributed to $\mathrm{ZrH}_{2}$ and $\mathrm{HfH}_{1.74}$, which were the closest reported hydride phases in the JCPDS database. The exact stoichiometries are here undetermined because transition metal hydrides are insertion compounds with hydrogen atoms in the interstitial positions: the number of hydrogen atom per atom of metal can range from 0.8 to 2 for $\mathrm{Zr}$ and $\mathrm{Hf}$ with little impact on the PXRD spectra. On diffractogram A, peaks at $33.0^{\circ}$ and $38.3^{\circ}$ (indicated by blue dashed lines) were attributed to ZrC. Early transition metal carbides are known to be nonstoichiometric due to carbon vacancies: zirconium and hafnium carbides are solid solutions with a continuum of stoichiometries from $\mathrm{MC}_{0.5}$ to $\mathrm{MC}_{1.0}$ with small variations of the cell parameters (respectively $0.17 \%$ and $0.5 \%$ of variation between the two extremes). ${ }^{[5]}$ Here, the peaks are broadened due to the small size of the crystallites and the precise stoichiometry of the carbide cannot be stated. ${ }^{[26]}$ All the powders were washed with ethanol and water and then exposed to air, surface oxidation is therefore expected. Accordingly, the diffractograms display a peak at respectively $30.2^{\circ}$ and $30.4^{\circ}$ (indicated by violet dashed lines) attributed to $\mathrm{ZrO}_{2}$ and $\mathrm{HfO}_{2}$ respectively (Figure 1A-B). Although the Scherrer formula could not be applied using these peaks, their broadness indicates a small crystallite size or an amorphous phase. 
Group V metals. On diffractograms C and D of Figure 1, peaks at respectively $34.4^{\circ}$ and $34.9^{\circ}$ (indicated by blue dashed lines) were attributed to $\mathrm{Nb}_{6} \mathrm{C}_{5}$ and $\mathrm{TaC}$. By reaction of metal with graphite, different phases of niobium and tantalum carbides can be obtained below $1500{ }^{\circ} \mathrm{C}: \mathrm{M}(0), \beta-\mathrm{M}_{2} \mathrm{C}, \mathrm{M}_{6} \mathrm{C}_{5}, \zeta-\mathrm{M}_{4} \mathrm{C}_{3}$ and $\delta$-MC. ${ }^{[27]}$ Diffraction patterns of $\mathrm{Nb}_{6} \mathrm{C}_{5}, \zeta-$ $\mathrm{Nb}_{4} \mathrm{C}_{3}$ and $\delta$ - $\mathrm{NbC}$ are close and our experimental diffraction patterns could match each of them. We arbitrarily chose to indicate $\mathrm{Nb}_{6} \mathrm{C}_{5}$ and $\mathrm{TaC}$ on the figure. $\mathrm{TaO}$ is isostructural with $\mathrm{TaC}$ and presents the same lattice parameters: its presence cannot be excluded at this point. Metal hydrides $\mathrm{NbH}_{0.8}$ and $\mathrm{TaH}_{0.5}$ are also detected at $36.1^{\circ}$ and $37.6^{\circ}$ respectively (indicated by green dashed lines). $\mathrm{NbH}_{0.8}$ pattern was a better match than $\mathrm{NbH}$ and other $\mathrm{H}$-richer niobium hydrides. We hypothesized the pronounced triangular shape of the peaks obtained with $\mathrm{TaCl}_{5}$ is due to the superposition of broad and thin diffraction peaks, resulting from the polydispersity in size of the crystallites.

Group VI metals. On diffractograms E and F, peaks at respectively $40.5^{\circ}$ and $40.3^{\circ}$ (indicated by red dashed lines) are attributed to $\mathrm{Mo}(0)$ and $\mathrm{W}(0) . \mathrm{KCl}$ salt generates a diffraction peak at $40.5^{\circ}$ which is almost underneath the first diffraction peak of metallic molybdenum and tungsten, hence the shoulder which appears at the right of the peak of $\mathrm{W}(0)$ at $40.3^{\circ}$. Metal carbides $\mathrm{M}_{2} \mathrm{C}$ (indicated by blue dashed lines) are also present for both metals. Tungsten and molybdenum carbides contain small amounts of carbon vacancies and the phase stoichiometries are more precise than for Group IV and V metal carbides. Starting from $\mathrm{MoCl}_{5}$, a single phase of hexagonal $\beta-\mathrm{Mo}_{2} \mathrm{C}$ was obtained, which corresponds to the most common molybdenum carbide and the most thermally stable, the other one being $\alpha$-MoC. In spite of the excess of carbon, the major phase obtained with tungsten was $\beta-\mathrm{W}_{2} \mathrm{C}$ and not WC. ${ }^{[28]}$

Overview. All the reactions described above result in metallic, metal carbide and/or metal hydride phases. The reactions with the six chloride salts were also conducted under 
static vacuum and an overview of the results is displayed in Figure S3. They display fairly similar behaviors than the reactions conducted under argon. Phase speciation for metals in the same column present strong similarities:

(1) metal chlorides of the Group IV ( $\mathrm{Zr}$ and Hf) form a mixture of mainly the metal(0) and the metal hydride $\mathrm{MH}_{y}$ but also of the metal carbide $\mathrm{MC}$ for $\mathrm{Zr}$ and of traces of the metal oxide $\mathrm{MO}_{2}$,

(2) metal chlorides of the Group $\mathrm{V}\left(\mathrm{Nb}\right.$ and $\mathrm{Ta}$ ) form either the metal hydride $\mathrm{MH}_{y}$ or the metal carbide $\mathrm{MC}$ in varying proportions under vacuum and in $\mathrm{Ar}$,

(3) metal chlorides of the Group VI (Mo and W) form mainly the metal(0) and the carbide $\mathrm{M}_{2} \mathrm{C}$.

Morphology description. Scanning Electron Microscopy (SEM) images reveal a homogeneous aspect of the samples at a length-scale larger than the micron (Figure S24). All samples were studied by Transmission Electron Microscopy (TEM), after washing, for morphology description and most of the sample corresponds to 5-25 $\mathrm{nm}$ large nanoparticles supported on carbon and nanostructured zones with nanostructuration length of the same order of magnitude (Figure S20 and S21). These zones look like the sintering of several particles. None of these objects are spherical. No objects larger than the initial size of the carbon support particles were observed (Figure S19). High resolution STEM discloses the presence of smaller particles or clusters (Figure S23A-D). The different objects are systematically obtained from a batch to another: the diversity therefore does not originate from variability between experiments but rather from an inhomogeneity of the reaction medium. In a few samples of syntheses from $\mathrm{MoCl}_{5}$ and $\mathrm{WCl}_{6}$, metallic particles present a core-shell morphology (core and shell of typically $10 \mathrm{~nm}$, Figure S23E-F) whose origin and composition are discussed later in this study. 
Surface oxidation state. X-ray Photoelectron Spectroscopy (XPS) performed on NPs synthesized under $\mathrm{Ar}$ from $\mathrm{MoCl}_{5}$ and $\mathrm{KC}_{4}$, and subsequently washed with water and exposed to air, unsurprisingly confirms the presence of surface oxidation with a species at $232.7 \mathrm{eV}$ (3d5/2 peak) in the Mo 3d region (Figure 2A). The presence of reduced molybdenum was noted with a peak at $228.4 \mathrm{eV}$ ( $3 \mathrm{~d} 5 / 2$ peak). It can be attributed both to $\mathrm{Mo}(0)$ and $\mathrm{Mo}_{2} \mathrm{C}$ species. Considering the penetration depth of the XPS technique (1-2 nm for Mo), only the extreme surface of the nanoparticles was probed here. ${ }^{[29]}$ Because XPS is a surface-sensitive method, the molybdenum sample was also analyzed with $\mathrm{X}$-ray Absorption Near-Edge Spectroscopy (XANES) at the Mo K-edge in order to determine the average oxidation state of the atoms in the nanoparticles. On Figure $2 \mathrm{~B}$, the spectrum of the sample is compared with three reference samples: metallic $\mathrm{Mo}(0), \mathrm{MoO}_{2}$ and $\mathrm{MoO}_{3}$. None of these compounds has a spectroscopic signature close to that of the sample. However, the edge position of the Mo nano-carbide is located at $20007.5 \mathrm{eV}$, closer to the $\mathrm{Mo}(0)$ metallic edge $(20003.9 \mathrm{eV})$ than to these of the oxides $\mathrm{MoO}_{2}$ and $\mathrm{MoO}_{3}(20016.5 \mathrm{eV}$ and $20020.5 \mathrm{eV}$, respectively). The spectrum of the sample is even closer to the spectrum of molybdenum carbide from literature. ${ }^{[30,31]}$ In particular, features (a), (b) and (c) on Figure 2B (respectively, a shoulder at ca. $20011 \mathrm{eV}$, an inflexion at ca. $20033 \mathrm{eV}$ and a maximum at $c a .20039 \mathrm{eV}$ ) are similar to the ones observed for the samples $\mathrm{MoC}-\mathrm{G}$ and $\mathrm{Mo}_{2} \mathrm{C}-\mathrm{G}$ from ref ${ }^{[31]}$. Overall, $\mathrm{Mo}_{2} \mathrm{C}$ describes the best the average environment of Mo atoms in the sample, in agreement with PXRD observations. XANES thus confirms that the main product is reduced molybdenum, although this is not clear from XPS measurements. We attribute this discrepancy to the fact that XPS can only probe the extreme surface containing oxidized species. The limited depth of oxidation of the nanoparticles is supported by the fact we observed distinct diffraction fringes of $\mathrm{Mo}_{2} \mathrm{C}$ phase on nanoparticles as small as $5 \mathrm{~nm}$ in diameter which were washed with ethanol and water (Figure S22). 
Samples of other metals were also analyzed by XPS (Figures S26 and S27). The metal is mostly observed at an elevated oxidation degree ( +4 for $\mathrm{Zr}$ and $\mathrm{Hf},+5$ for $\mathrm{Nb}$ and $\mathrm{Ta},+6$ for W). The signals corresponding to $\mathrm{W}(\mathrm{IV}), \mathrm{Mo}(\mathrm{II})$ and $\mathrm{Nb}(\mathrm{II})$, respectively at $244.1,293.3$ and 204.4 eV on Figure S26E, S26C and S26B indicate the possible presence of suboxides species at the interface between the oxide surface and the metallic core.
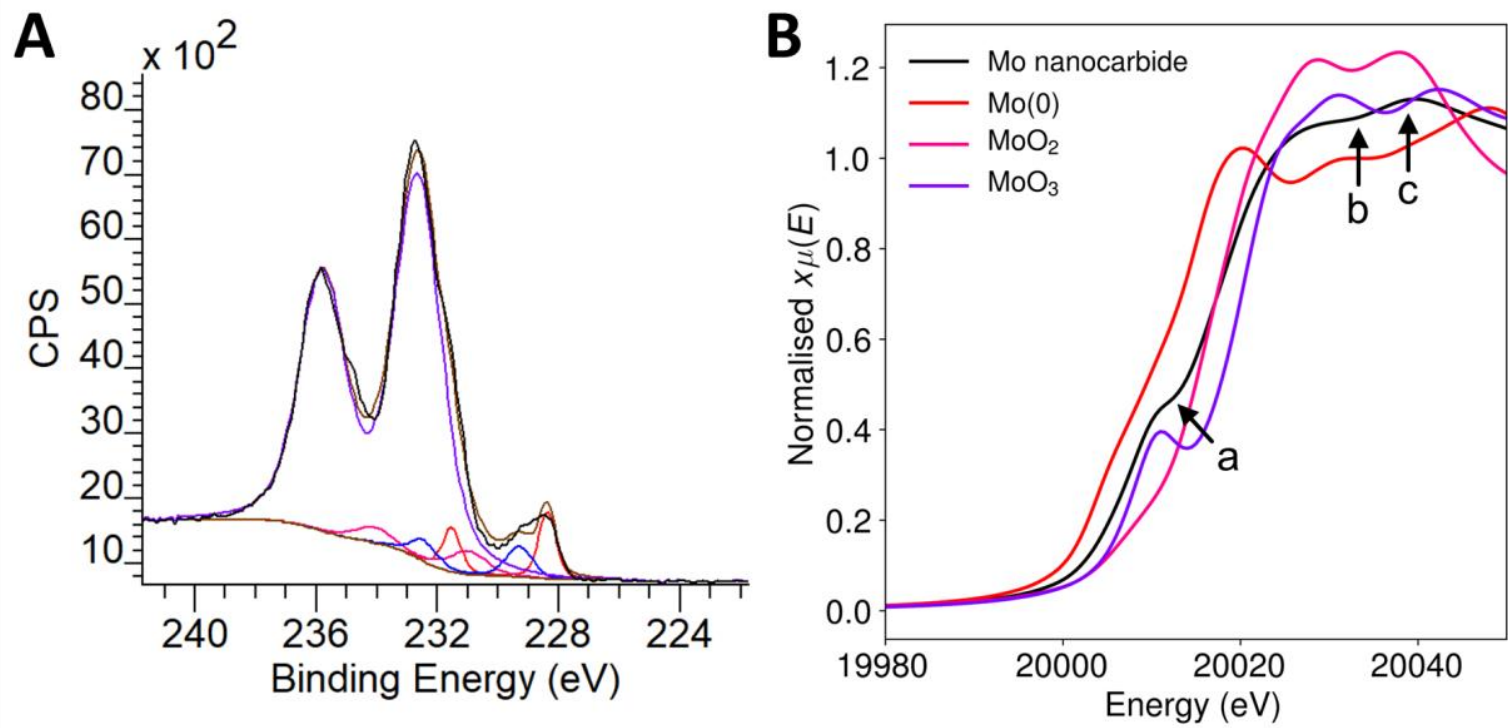

Figure 2. Redox state of sample Mo nanocarbide from XPS and Mo K-edge XANES measurements. (A) XPS of the Mo 3d region, black: measured signal, red: contributions attributed to $\mathrm{Mo}(0)$, blue: $\mathrm{Mo}(+\mathrm{II})$, magenta: $\mathrm{Mo}(+\mathrm{IV})$, purple: $\mathrm{Mo}(+\mathrm{VI})$, brown: sum of all 4 contributions. (B) Mo K-edge XANES measurements, black: sample Mo nanocarbide pellet, red: $\mathrm{Mo}(0)$ sheet, magenta: $\mathrm{MoO}_{2}$ pellet, purple: $\mathrm{MoO}_{3}$ pellet. Features (a), (b) and (c) are features characteristic of the signal of molybdenum carbide.

Bimetallic nanoparticles. Attempts were made to synthesize bimetallic nanoparticles by mixing two chloride salts in equal proportions: $\mathrm{ZrCl}_{4}$ and $\mathrm{MoCl}_{5}, \mathrm{ZrCl}_{4}$ and $\mathrm{WCl}_{6}, \mathrm{MoCl}_{5}$ and $\mathrm{WCl}_{6}$. The PXRD of the final powders display the phases obtained with the two chloride salts (Figures S15-17), suggesting that two independent reactions occurred. None of these experiments led to the targeted phases $\mathrm{M}^{\prime} \mathrm{M}^{\prime}{ }^{\prime} \mathrm{C}_{2}$ (the most common reported mixed metal carbide phases). Electron Dispersive X-ray Spectroscopy (EDS) reveals the ratio between the 
two metallic elements is close to 1 (1.1 for ZrMo, 0.9 for $\mathrm{ZrW}$ and 0.9 for MoW) (Table S57), indicating that the extent of reaction was roughly the same for each metal. Mixed carbide phases are obtained by other works on solid-sate metathesis. Here, the contact between the three reagents by handshaking is probably not intimate enough to produce mixed carbides. These results support the hypothesis that the reaction between $\mathrm{KC}_{4} / \mathrm{KC}_{8}$ and metal chlorides is controlled by the process rather than being under thermodynamic control.

Combustion temperature. Reactions with $\mathrm{ZrCl}_{4}$ and $\mathrm{HfCl}_{4}$ are less explosive than the ones with $\mathrm{NbCl}_{5}, \mathrm{TaCl}_{5}$ and $\mathrm{MoCl}_{5}$, themselves less explosive than the one with $\mathrm{WCl}_{6}$ (see Figure 1 for snapshots and Videos in SI for full reactions in $\mathrm{Ar}$ or under vacuum). The combustion temperature, i.e. the highest temperature reached during the explosion, is expected to be one of the key parameters for the phase speciation of the metal. Considering the brevity of the reaction, $c a$. one second, and its high exothermicity, a large amount of energy is liberated in a short period of time and a small space, leading to high temperatures. As a first approach of the released energy by the SSM reaction, we can compare the differences of standard electrochemical potentials $\left(\Delta \mathrm{E}^{\circ}=\mathrm{E}^{\circ}\left(\mathrm{MCl}_{x}\right)-\mathrm{E}^{\circ}(\mathrm{K})\right)$ between $\mathrm{K}$ and $\mathrm{MCl}_{x}$ for the different metal chlorides. Standard potentials are not reported for all the chloride salts, we therefore compare the $\Delta \mathrm{E}^{\circ}$ with metal oxides of similar degrees of oxidation $\left(\mathrm{ZrO}_{2}\right.$, $\mathrm{HfO}_{2}, \mathrm{Nb}_{2} \mathrm{O}_{5}, \mathrm{Ta}_{2} \mathrm{O}_{5}, \mathrm{WO}_{3}$ ) (Table 1, column 1). A larger difference in standard potentials corresponds to an easier and more exothermic reduction of the corresponding metal chloride and thus to a more violent reaction. Metal oxides from the same column have similar redox potentials and $\Delta \mathrm{E}^{\circ}$ increases from Group IV to Group VI (around 1.4 V for Group IV, $2.2 \mathrm{~V}$ for Group V and above $2.8 \mathrm{~V}$ for Group VI). This is consistent with the increase in exothermicity observed on Figure 1 and in the videos. 


\begin{tabular}{|c|c|c|c|c|c|}
\hline $\mathbf{N}^{\circ}$ & 1 & 2 & 3 & 4 & 5 \\
\hline $\begin{array}{l}\text { Metal } \\
\text { salt }\end{array}$ & $\begin{array}{c}\Delta \mathrm{E}^{\circ} \\
\text { potassium- } \\
\text { oxides }\end{array}$ & $\begin{array}{l}\text { Released } \\
\text { energy } \\
(\mathrm{kJ} / \mathrm{mol})\end{array}$ & $\begin{array}{l}\text { Adiabatic } \\
\text { temperature } \\
\mathrm{T}_{\mathrm{ad}}\end{array}$ & $\begin{array}{l}\text { Chloride salt } \\
\qquad \mathrm{T}_{\mathrm{m}}\end{array}$ & $\begin{array}{l}\text { Carbide Gibbs energy of } \\
\text { formation at } 1500{ }^{\circ} \mathrm{C}(\mathrm{kJ} / \mathrm{mol})\end{array}$ \\
\hline $\mathrm{ZrCl}_{4}$ & $1.38 \mathrm{~V}$ & 642 & $990^{\circ} \mathrm{C}$ & $331^{\circ} \mathrm{C}$ (sub.) & $-181(\mathrm{ZrC})$ \\
\hline $\mathrm{HfCl}_{4}$ & $1.42 \mathrm{~V}$ & 633 & $970{ }^{\circ} \mathrm{C}$ & $432{ }^{\circ} \mathrm{C}$ & $*$ \\
\hline $\mathrm{NbCl}_{5}$ & $2.29 \mathrm{~V}$ & 1231 & $1490^{\circ} \mathrm{C}$ & $205^{\circ} \mathrm{C}$ & $-133(\mathrm{NbC})$ \\
\hline $\mathrm{TaCl}_{5}$ & $2.18 \mathrm{~V}$ & 1170 & $1420^{\circ} \mathrm{C}$ & $216^{\circ} \mathrm{C}$ & $-140(\mathrm{TaC})$ \\
\hline $\mathrm{MoCl}_{3}$ & $*$ & 824 & $1500^{\circ} \mathrm{C}$ & $410^{\circ} \mathrm{C}$ & $-63\left(\mathrm{Mo}_{2} \mathrm{C}\right)$ \\
\hline $\mathrm{MoCl}_{5}$ & $2.89 \mathrm{~V} *$ & 1502 & $1500^{\circ} \mathrm{C}$ & $194^{\circ} \mathrm{C}$ & $-63\left(\mathrm{Mo}_{2} \mathrm{C}\right)$ \\
\hline $\mathrm{WCl}_{6}$ & $2.84 \mathrm{~V}$ & 1841 & $1500^{\circ} \mathrm{C}$ & $275^{\circ} \mathrm{C}$ & $\begin{array}{c}-38\left(\mathrm{~W}_{2} \mathrm{C}\right) \\
\text { and }-33(\mathrm{WC})\end{array}$ \\
\hline
\end{tabular}

*No data available. For $\mathrm{Mo}(\mathrm{V})$ : we used the average $\mathrm{E}^{\circ}$ of $\mathrm{MoO}_{2}(0.15 \mathrm{~V})$ and $\mathrm{MoO}_{3}(0.07 \mathrm{~V})$

Table 1. Thermodynamic considerations for the reactions conducted on the different metal chlorides with stoichiometric proportions of $\mathrm{KC}_{4}$. (1) Difference in standard potential $\mathrm{E}^{\circ}$ between potassium $(-2.93 \mathrm{~V})$ and the corresponding oxide. The redox half-equations are given in water with $\mathrm{M}(0)$ as the reducing agent. ${ }^{[32]}$ (2) Absolute value of molar reaction enthalpy of the reaction of formation of the metal. ${ }^{[33]}$ (3) Adiabatic temperature $T_{a d}$ determined with Eq. 2 and considering the eventual melting and evaporation of $\mathrm{KCl}$. (4) Melting temperature of the corresponding chloride salt (for $\mathrm{ZrCl}_{4}$, sublimation temperature). (5) Standard Gibbs energy of formation, per atom carbon, of the most common carbide phases from elemental reagents $(\mathrm{M}(0)$ and graphite).

A more rigorous approach for the exothermicity of the reactions is the calculation of the reaction enthalpy. To calculate it, we define the ignition temperature $T_{\text {ig }}$ as the temperature at which the reaction is triggered in the powder mixture. The heat released by the reaction at $T_{i g}$, noted $\left|\Delta_{\text {reaction }} \mathrm{H}_{\mathrm{T}}^{0}\right|$, corresponds to the absolute value of the enthalpy of reaction, i.e. the difference in enthalpy of formation between the reagents and the products. It can be calculated using Hess's law, the useful data for the calculations of released energy by the reaction are 
given in Table S2 and the results in Table 1, column 2 and Table S3. The high exothermicity of the reaction is due to the large negative enthalpy of formation of the coproduced salt $\mathrm{KCl}$. To simplify the thermodynamic calculations, we made the assumption that $\mathrm{M}(0), \mathrm{KCl}$ and graphitic carbon are the only products and we did not take into account the formation of carbides which is also exothermic but in a smaller extent. We also assumed the conversion is total. The change in the enthalpy of formation of the different chloride salts between room temperature and the ignition temperature (always inferior to $75^{\circ} \mathrm{C}$ ) can be neglected as it is below $1 \%$ between room temperature and $75^{\circ} \mathrm{C}(c f$. Ellingham approximation). The estimated energies released during the explosion are consistent with the visual observations of the reaction and with the $\Delta \mathrm{E}^{\circ}$ : reactions with chlorides of metals of Group IV liberate less heat than reactions with metals of Group V and Group VI, the more exothermic reaction being the one with $\mathrm{WCl}_{6}$.

We define the adiabatic temperature $T_{a d}$ as the theoretical maximum temperature reached by the mixture if we consider the system as thermally isolated. $\mathrm{T}_{\mathrm{ad}}$ is a theoretical temperature, to be distinguished from the actual temperature during the reaction, termed combustion temperature and noted $\mathrm{T}_{\text {comb }}$. It seems reasonable to consider the system as pseudo-adiabatic considering the brevity of the reaction. All the energy released by the reaction is then dissipated in the heating of the powder and eventual endothermic state changes (melting and evaporation of $\mathrm{KCl})$. As the enthalpy is a state function, $\mathrm{T}_{\mathrm{ad}}$ may be defined independently on how the system actually reaches its final state (Figure 3 ). ${ }^{[8]}$ We note $C_{p}$ the heat capacity of the products $(\mathrm{KCl}$ salt, graphite and metal( $(0))$, it is a function of the temperature and of the physical state of the compounds, the models we chose for its value are given in SI. $\mathrm{T}_{\mathrm{ad}}$ is determined by Eq. 2: if $\mathrm{T}_{\mathrm{ad}}$ is beyond the melting point $\mathrm{T}_{\text {fus }}\left(770{ }^{\circ} \mathrm{C}\right)$ or the boiling point $\mathrm{T}_{\text {vap }}$ $\left(1500{ }^{\circ} \mathrm{C}\right)$ of $\mathrm{KCl}$, we also have to take into account the enthalpy of fusion $\Delta \mathrm{H}_{\text {fus }}^{0}(\mathrm{KCl})$ and the enthalpy of evaporation $\Delta \mathrm{H}_{\mathrm{vap}}^{0}(\mathrm{KCl})$ of sylvite. ${ }^{[7]}$ All the other compounds (metals, 
carbides and graphite) have melting or degradation temperatures far beyond the boiling point of potassium chloride and their physical state do not change on the temperature range relevant here.

$$
\left|\Delta_{\text {reaction }} H_{T_{\text {ig }}}^{0}\right|=\int_{T_{\text {ig }}}^{T_{\text {fus }}} \mathrm{C}_{\mathrm{p}}(\mathrm{T}) \mathrm{dT}+\mathrm{x} \Delta \mathrm{H}_{\text {fus }}^{0}(\mathrm{KCl})+\int_{\mathrm{T}_{\text {fus }}}^{\mathrm{T}_{\mathrm{ad}}} \mathrm{C}_{\mathrm{p}}(\mathrm{T}) \mathrm{dT}
$$

This method does not pretend to give an exact value of the combustion temperature $\mathrm{T}_{\text {comb }}$, however it gives an upper limit: the adiabatic temperature $\mathrm{T}_{\mathrm{ad}}$. The actual combustion temperatures are certainly lower due to a limited conversion and to the heat transfers towards the Schlenk tube walls and to the gas phase when there is one. A similar study about the sulfuration of $\mathrm{MoCl}_{5}$ with $\mathrm{Na}_{2} \mathrm{~S}$ to form $\mathrm{Mo}_{2} \mathrm{~S}$ gave an adiabatic temperature of $1450{ }^{\circ} \mathrm{C}$ (boiling point of $\mathrm{NaCl}$ ) and optical pyrometry measurements indicated an actual temperature close to $1100{ }^{\circ} \mathrm{C}^{[7]}$ The reaction is conducted on small quantities $(\approx 0.2 \mathrm{mmol}$ of chloride salt) and the released energy is eventually absorbed by the Schlenk tube: the temperature elevation does not exceed $45{ }^{\circ} \mathrm{C}$ (calculations in SI). All the reactions presented here have $\mathrm{T}_{\mathrm{ad}}$ close or above $1000{ }^{\circ} \mathrm{C}$ (Table 1, column 3) except metals from Group IV whose adiabatic temperatures are approximately $400{ }^{\circ} \mathrm{C}$ lower than these of the other metals.

The combustion temperatures are high enough to exceed the metal chloride melting points (Table 1, column 4), therefore, as soon as the reaction initiates, the metal chloride melts and triggers the reaction in its vicinity: it thus propagates the reaction zone, maintaining a high temperature until all the reagents are consumed (Figure S1). 

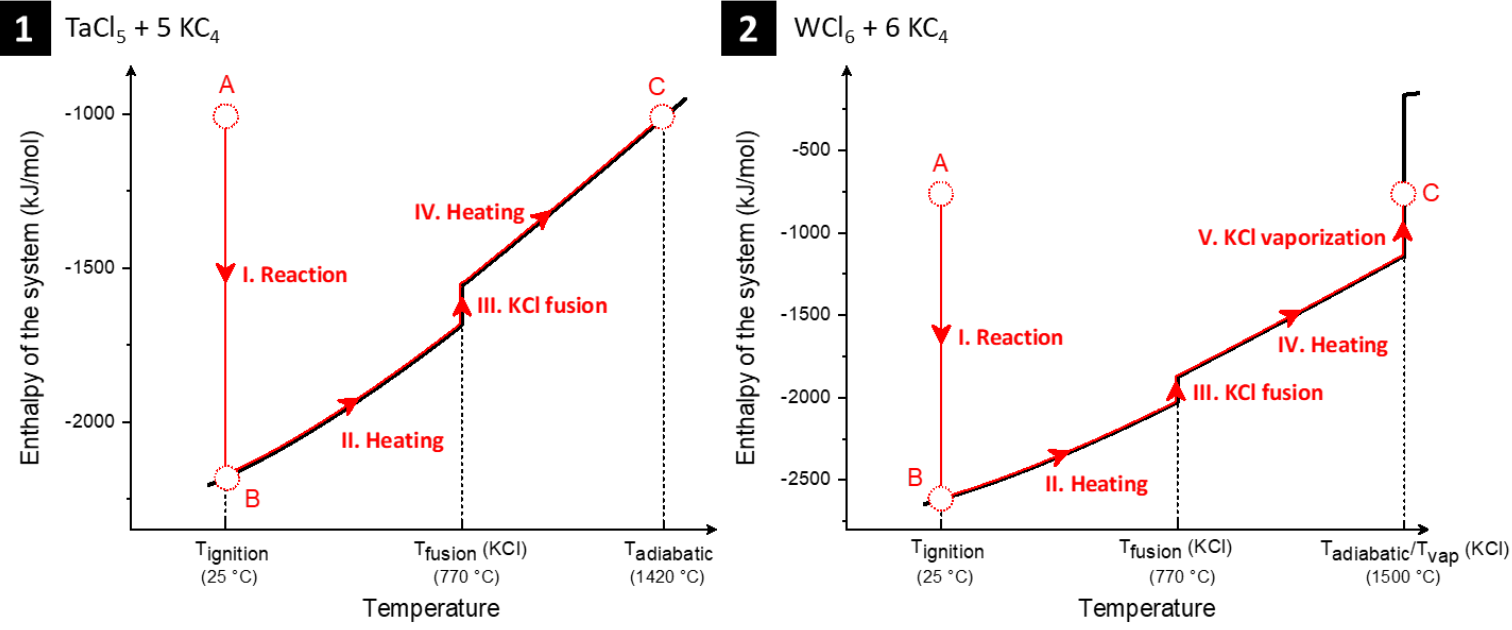

Figure 3. Illustrations of a hypothetical thermodynamic pathway of the reaction (1) $\mathrm{TaCl}_{5}+5 \mathrm{KC}_{4} \rightarrow \mathrm{Ta}(0)+5 \mathrm{KCl}+20 \mathrm{C}$ and (2) $\mathrm{WCl}_{6}+6 \mathrm{KC}_{4} \rightarrow \mathrm{W}(0)+6 \mathrm{KCl}+24 \mathrm{C}$. (A) Initial state before reaction starts, (B) hypothetical state just after reaction but before temperature elevation, $(\mathrm{C})$ final state of the system at the adiabatic temperature $\mathrm{T}_{\mathrm{ad}}$. $\mathrm{A}$ and $\mathrm{C}$ correspond to an equal total enthalpy of the system.

Modified Solid-State Metathesis (MSSM). A similar reaction was attempted on carbon dispersed potassium $\left(\mathrm{KC}_{4}\right)$ and molybdenum oxide $\left(\mathrm{MoO}_{3}\right)$ precursor instead of molybdenum chloride $\left(\mathrm{MoCl}_{5}\right)$. This Modified Solid-State Metathesis (MSSM, "modified" as the precursor is an oxide and not a chloride) presents the advantages of a cheap and stable precursor. The reaction failed to produce carbides or any other products even if the mixture was heated above $100{ }^{\circ} \mathrm{C}$. If we consider the reaction equation Eq. 3, the reaction enthalpy for $\mathrm{MoO}_{3}$ is -160 $\mathrm{kJ} / \mathrm{mol}$. If we compare this value with the enthalpies of reaction with metal chlorides, comprised between $-623 \mathrm{~kJ} / \mathrm{mol}$ and $-1841 \mathrm{~kJ} / \mathrm{mol}$, we can conclude the low exothermicity of the reaction with $\mathrm{MoO}_{3}$ impends the self-propagation via high temperatures.

$$
\mathrm{MO}_{z}+2 z \mathrm{KC}_{4} \rightarrow[\mathrm{M}]+z \mathrm{~K}_{2} \mathrm{O}+\text { excess } \mathrm{C}
$$

Calculations made for the other metal oxides led to less exothermic reactions, or even endothermic ones (all the results are given in Table S3). The difference between MSSM and SSM in our case is the important difference in standard enthalpy of formation of the coproduced salt $\left(-394 \mathrm{~kJ} / \mathrm{mol}\right.$ for $\mathrm{K}_{2} \mathrm{O}$ vs. $-818 \mathrm{~kJ} / \mathrm{mol}$ for $\left.2 \mathrm{KCl}\right)$. Sylvite $(\mathrm{KCl})$ is a thermodynamic well which leads to a strongly exothermic reaction, contrarily to $\mathrm{K}_{2} \mathrm{O}$. 
Nonetheless, MSSM for carbide synthesis was successfully reported in other studies when the reducing agent was $\mathrm{CaC}_{2}$ or $\mathrm{SrC}_{2}$ : this is made possible by the large enthalpy of formation of $\mathrm{CaO}$ and $\mathrm{SrO}$ (respectively $-635.7 \mathrm{~kJ} / \mathrm{mol}$ and $-592 \mathrm{~kJ} / \mathrm{mol}$ ). ${ }^{[21]}$ The experimental validation of the reactivity of $\mathrm{KC}_{4}, \mathrm{KC}_{8}, \mathrm{CaC}_{2}$ and $\mathrm{SrC}_{2}$ with metal chlorides and of only $\mathrm{CaC}_{2}$ and $\mathrm{SrC}_{2}$ with metal oxides confirms the pertinence of our model for calculating enthalpies of reaction.

Thermodynamic control versus process control. All the Gibbs energies of formation of the carbide phases from the metal $(0)$ and elemental carbon $\left(\Delta \mathrm{G}_{\mathrm{f}}^{0}\right.$ (carbides)) are negative (Table 1, column 5) and the system presents large excess of graphitic carbon, 20 atoms of $\mathrm{C}$ at minima per metal atom. If the system had reached a thermodynamic equilibrium, there should be no metal( $(0)$ left to the benefice of carbide. On the contrary, metal( 0$)$ and hydride phases, deriving from metal(0), were detected, and in higher proportions for Group IV metals than for Group VI ones whereas the Gibbs energy of formation of the carbide is higher for $\mathrm{Mo}_{2} \mathrm{C}$ and $\mathrm{W}_{2} \mathrm{C}$ than for $\mathrm{ZrC}$ and $\mathrm{HfC}$. This consideration comforts our hypothesis that the reaction is under kinetic control and not thermodynamic one. In this system, the reaction products speciation is in great part led by the combustion temperature and the quality of the reagents contact, these two points being themselves related to different process parameters. 


\subsection{Process parameters}

The reaction between the chloride salts and potassium is not under thermodynamic control as shown previously. We therefore studied the influence of different process parameters on the metal phase speciation. The pie-charts in this section which display the phase speciation of the crystalline part must be considered as a trend rather than absolute ratios: regular PXRD is not a quantitative method. Methods for quantifying exactly the proportion of each phase are beyond the scope of this study as only the evolution of the proportions are relevant here. For readability, comparisons of diffractograms are displayed only on a small angle range showing relevant peaks but full range diffractograms $\left(20-80^{\circ}\right)$ are reported in SI (Figures S5-14). The reactions were all performed twice and the results are rather reproducible although the reactions are delicate to conduct. The commented trends are stable and consistent through the different studied metals.

Carbon source. The nature of the carbon support, acetylene black vs. graphite, was identified as having an importance on the proportion of carbide vs. metal for Group VI metals. In the case of $\mathrm{MoCl}_{5}$, there is more carbide when the reaction is performed with potassium graphite $\left(\mathrm{KC}_{8}\right)$ than with potassium acetylene black $\left(\mathrm{KC}_{4}\right)$ (Figure $\left.3 \mathrm{~A}\right)$. Similar results were obtained with $\mathrm{WCl}_{6}$ (Figures S9-10 and S13-14). The difference in enthalpy of formation of $\mathrm{KC}_{4}$ and $\mathrm{KC}_{8}$ is of $2.5 \mathrm{~kJ} / \mathrm{mol}$ so the relative change in enthalpy reaction is below $2 \%$ : the heat released by the reaction is virtually the same with $\mathrm{KC}_{4}$ and $\mathrm{KC}_{8}$. The quantity of carbon is however doubled, increasing the heat capacity of the medium and limiting thereby the combustion temperature. The decrease in the adiabatic temperature from $\mathrm{KC}_{4}$ to $\mathrm{KC}_{8}$ is between $200{ }^{\circ} \mathrm{C}$ and $400{ }^{\circ} \mathrm{C}$ (Table S4). If we consider the carbide phase as the phase favored by high temperatures (due to carbon diffusion in the metal), this explanation based on the reaction enthalpy goes against the observed trend as the proportion of carbide should increase with adiabatic temperature and should therefore be higher with $\mathrm{KC}_{4}$, which is not the case. 
The origin of the difference between $\mathrm{KC}_{4}$ and $\mathrm{KC}_{8}$ reactions could not be definitely identified but several hypotheses are proposed. The graphitic carbon may be more easily decomposed than acetylene black and thus diffuses more quickly in metal NPs. The contact between the two precursors powders may be more intimate for graphite than for acetylene black due for instance to the grain size and self-cohesion of the powder. Finally, as $\mathrm{KC}_{8}$ is more compact than $\mathrm{KC}_{4}$, the explosion disperses less the mixture of powders (as observed with a naked eye) and the heat dissipation may be lower for $\mathrm{KC}_{8}$ leading to higher temperatures locally, hence a better carbon insertion.

Precursor grain size. Particle size of $\mathrm{MoCl}_{5}$ and $\mathrm{WCl}_{6}$ was found to influence the phase speciation of the products, in favor of the metal for an increasing grain size (Figure 3BC, S9-10 and S13-14). To generate bigger crystal grains, two precursors, $\mathrm{MoCl}_{5}$ and $\mathrm{WCl}_{6}$, were recrystallized under vacuum at $210{ }^{\circ} \mathrm{C}$ and the product was collected and used as is without grinding. Due to the air degradation of the precursors, no quantitative measurements of the grain size of the recrystallized powders of $\mathrm{MoCl}_{5}$ and $\mathrm{WCl}_{6}$ were performed but a picture of the two powders gives an order of magnitude of the respective granularities (Figure S2): the commercial powder has granularity below $1 \mathrm{~mm}$ whereas that of recrystallized precursors is above. An increase in the precursor grain size leads to a lower contact area between the reagents. This may result in a lower conversion if not all the precursor has reacted. The loss in heat released by the reaction may lead to a lower combustion temperature and therefore explain the lower conversion to carbide. 


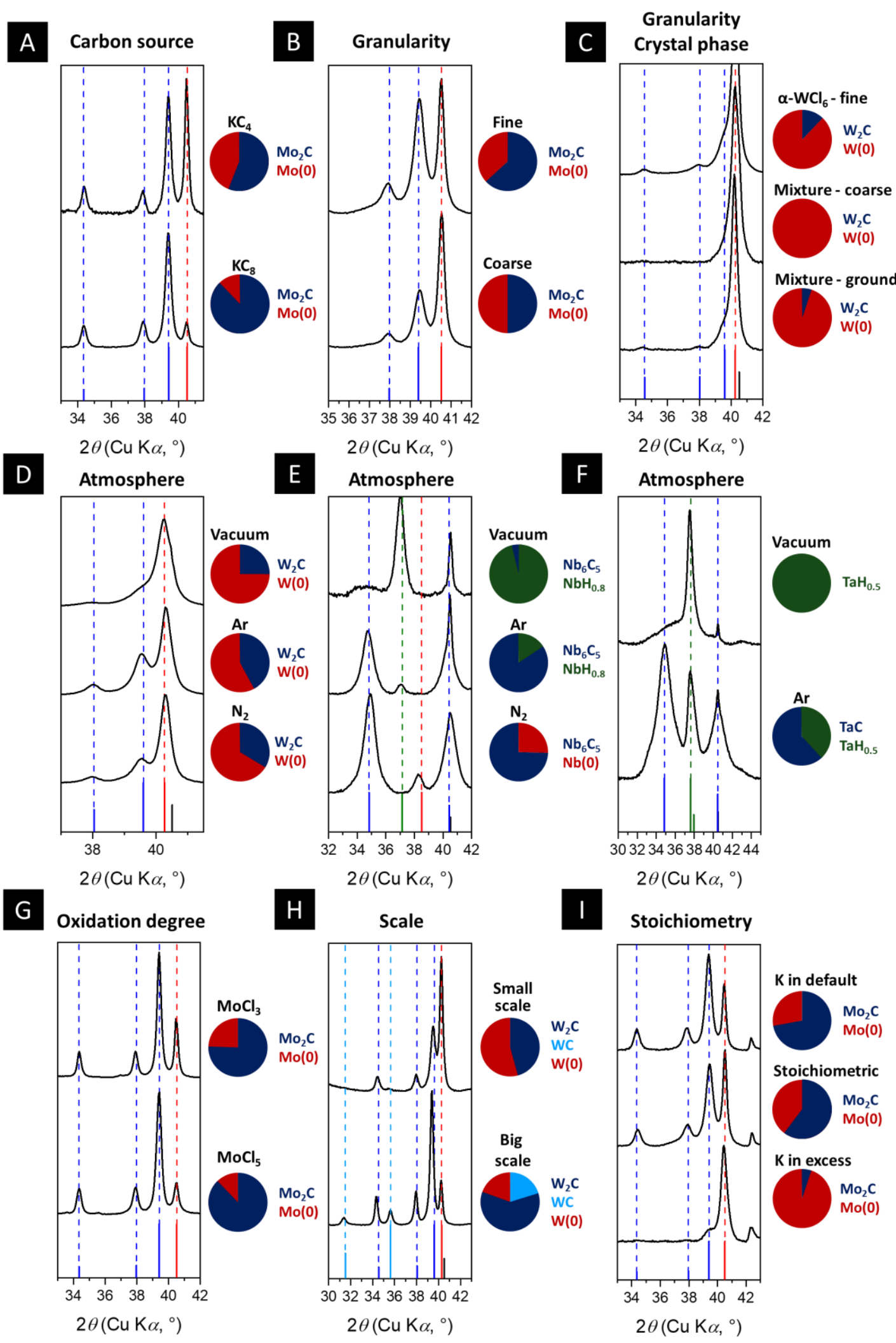

Figure 4. Details of diffractograms of powders obtained by reaction with metal chlorides under different conditions. (A) $\mathrm{MoCl}_{5}$ under $\mathrm{Ar}$ with $\mathrm{KC}_{4} / \mathrm{KC}_{8}$, (B) $\mathrm{MoCl}_{5}$ fine/coarse under vacuum with $\mathrm{KC}_{8}(\mathrm{C}) \mathrm{WCl}_{6}$ fine/coarse/ground under vacuum with $\mathrm{KC}_{4}$, (D) $\mathrm{WCl}_{6}$ under vacuum/ $\mathrm{Ar} / \mathrm{N}_{2}$ with $\mathrm{KC}_{4}$ (E) $\mathrm{NbCl}_{5}$ under vacuum/Ar/ $\mathrm{N}_{2}$ with $\mathrm{KC}_{4}$, (F) $\mathrm{TaCl}_{5}$ under vacuum/ $\mathrm{Ar}$ with $\mathrm{KC}_{4},(\mathrm{G}) \mathrm{MoCl}_{3} / \mathrm{MoCl}_{5}$ under Ar with $\mathrm{KC}_{8},(\mathrm{H}), \mathrm{WCl}_{6}$ under Ar with $\mathrm{KC}_{4}$ at 
small/big scale and (I) $\mathrm{MoCl}_{5}$ under $\mathrm{Ar}$ with $\mathrm{KC}_{8}$ in default/in stoichiometric proportion/in excess. Pie charts are guides for the eyes of the repartition in the different phases.

Precursor crystal phase. As the reaction occurs between two solids, we investigated whether the crystal phase of the precursor could have an impact on the products. Tungsten hexachloride $\left(\mathrm{WCl}_{6}\right)$ displays two crystal phases: the $\alpha$-rhombohedral phase (corresponding to the commercial product) and the $\beta$-hexagonal phase. ${ }^{[34]}$ The recrystallization of $\alpha-\mathrm{WCl}_{6}$ at $210{ }^{\circ} \mathrm{C}$ under vacuum led to a mixture of $\alpha-\mathrm{WCl}_{6}$ and $\beta-\mathrm{WCl}_{6}$ (the phase transition at atmospheric pressure is tabulated at $177^{\circ} \mathrm{C}$ ). Although no absolute quantification of the two phases was performed by PXRD, we can estimate the major phase of the recrystallized compound is $\beta-\mathrm{WCl}_{6}$ (Figure S4), assuming they lead to a similar signal. To limit the influence of the granularity, the recrystallized mixture of $\alpha-\mathrm{WCl}_{6}$ and $\beta-\mathrm{WCl}_{6}$ was ground to obtain a finer powder, however not as fine as the commercial $\alpha-\mathrm{WCl}_{6}$ as extensive grinding seems to trigger a chemical reaction on $\mathrm{WCl}_{6}$ (beige-red coloration of the powder instead of deep purple). Whereas the peaks of tungsten carbide $\mathrm{W}_{2} \mathrm{C}\left(34.5^{\circ}, 38.0^{\circ}\right.$ and $\left.39.6^{\circ}\right)$ were not visible for coarse precursor grains, they reappear on the diffractogram of the reaction with "ground" $\mathrm{WCl}_{6}$ indicating the difference in metal speciation between commercial $\alpha-\mathrm{WCl}_{6}$ and the mixture of $\alpha-\mathrm{WCl}_{6}$ and $\beta-\mathrm{WCl}_{6}$ from the recrystallization is probably due to precursor granularity and not to crystal phase (Figure 3C). This result is supported by a difference of enthalpies of formation between $\alpha-\mathrm{WCl}_{6}$ and $\beta-\mathrm{WCl}_{6}$ of only $21 \mathrm{~kJ} / \mathrm{mol}$ at room temperature, accounting for a negligible change in the enthalpy of reaction of $1 \%$.

Inert gas $\left(\mathbf{A r} / \mathbf{N}_{2}\right)$ versus vacuum. The metal speciation radically changes whether the reaction is performed under vacuum or in $\mathrm{Ar}$ or $\mathrm{N}_{2}$-filled vessels. In the case of $\mathrm{MoCl}_{5}$ and $\mathrm{WCl}_{6}$, the absence of gas phase leads to a higher proportion of metal(0) vs. metal carbide $\mathrm{M}_{2} \mathrm{C}$ whereas the ratio $\mathrm{M}(0) / \mathrm{M}_{2} \mathrm{C}$ seems less affected by the nature of the gas $\left(\mathrm{Ar}\right.$ or $\mathrm{N}_{2}$ ) (Figure 4D). For Group V metals ( $\mathrm{Nb}$ and Ta), the only product detected is a hydride $\left(\mathrm{NbH}_{0.8}\right.$ and $\mathrm{TaH}_{0.5}$ ) when there is no gas phase (Figure 4E-F). The presence of hydrides may be 
surprising considering there is theoretically no stoichiometric source of hydrogen but we hypothesized the hydride NPs originate from the metallic NPs, this point will be discussed in detail later. The differences in the diffractograms are smaller between the experiments with the two gases than between gas and vacuum. Therefore, the impact of this parameter on the reaction does not originate from a chemical phenomenon linked to the nature of the gas molecules but rather from a physical phenomenon. We did not consider the heat dissipation by the gas phase as a credible explanation. Indeed, Ar has a molar heat capacity of $12.5 \mathrm{~J} / \mathrm{mol} / \mathrm{K}$ which corresponds to a heat capacity of $12.5 \mathrm{~mJ} / \mathrm{K}$ for the entire volume (25 mL) of the Schlenk tube. The energy needed to elevate the temperature of the gas of $1000{ }^{\circ} \mathrm{C}$ is $12.5 \mathrm{~J}$. The minimum energy released by the reaction of $0.29 \mathrm{mmol}$ of $\mathrm{HfCl}_{4}$ (the less exothermic reaction) is $152 \mathrm{~J}$. If the entire gas volume of the Schlenk was immediately heated to the combustion temperature, it would account for $8 \%$ of the total released energy. We do not estimate such a decrease of enthalpy would be enough to strongly modify the phase speciation. Moreover, considering the total time of reaction is below one second, it seems very unlikely that the whole gas phase would reach the combustion temperature. We can thus neglect, in a first approach, the heat capacity of the gas on the combustion temperature. Another possible explanation is the self-cohesion of the powder mixture: as mentioned earlier, a black particulate solid is spread over the Schlenk tube during the explosion and this is particularly true for reactions under vacuum (Figure S3). This may lead to a higher heat dissipation towards the Schlenk wall and therefore to lower combustion temperatures. Finally, the melting and boiling points of $\mathrm{KCl}$ decrease under vacuum which may also limit the combustion temperature. Even though we cannot decide the mechanism at stake here, this process parameter (gas phase) is clearly critical. We noticed that the reactions more often self-ignited (i.e. without heat gun activation) under vacuum, or sometimes during the gas evacuation, than similar reactions under inert gas. Conducting the reaction under 
vacuum leads to a lower ignition temperature (high reactivity) but to a lower combustion temperature too (low proportion of carbides vs. metal( $(0)$ and hydrides compared to reaction under $\operatorname{Ar}$ or $\mathrm{N}_{2}$ ).

Oxidation number. The reaction performed with a molybdenum chloride salt of lower degree of oxidation $\left(\mathrm{MoCl}_{3}\right.$ vs. $\left.\mathrm{MoCl}_{5}\right)$ led to the same metallic and carbide phases (Figure 4G). We also detect traces of unreacted $\mathrm{MoCl}_{3}$ which does not hydrolyze or degrade, even in water, to the contrary of $\mathrm{MoCl}_{5}$. The heat released by the reaction of $\mathrm{KC}_{8}$ with $\mathrm{MoCl}_{3}$ $(817 \mathrm{~kJ} / \mathrm{mol})$ is only $55 \%$ of the heat released by the reaction with $\mathrm{MoCl}_{5}(1489 \mathrm{~kJ} / \mathrm{mol})$ but the total heat capacity of the mixture from $\mathrm{MoCl}_{3}$ is $70 \%$ that of the one from $\mathrm{MoCl}_{5}$, we can therefore expect similar combustion temperatures. Experiments showed a comparable phase speciation of the molybdenum: we conclude the impact of the initial oxidation number is limited if close combustion temperatures are reached.

Scale. The reactions of this study were conducted at the scale of $100 \mathrm{mg}$ of $\mathrm{KC}_{4}$ or $155 \mathrm{mg}$ of $\mathrm{KC}_{8}$. The scale up of the reaction has an important impact on the phase speciation, at least for Mo and W. Figure $4 \mathrm{H}$ shows the diffractograms obtained for the reaction conducted on $\mathrm{WCl}_{6}$ and $\mathrm{KC}_{4}$ under Ar with $100 \mathrm{mg}$ and $500 \mathrm{mg}$ of $\mathrm{KC}_{4}$. The proportion of metallic particles is lowered when the scale is increased. Furthermore, another carbide, WC, was detected in addition of $\mathrm{W}_{2} \mathrm{C}$. We hypothesized the increase in mass of the reaction medium diminishes losses of heat by dissipation. Therefore, higher combustion temperatures may be attained, leading to a more complete carburization of the metallic NPs and more carbon-rich carbide phases. Indeed, WC is usually obtained at higher temperatures than $\mathrm{W}_{2} \mathrm{C}^{[35]}$

Stoichiometry. We finally explored the potential impact of a default or an excess of the reducing agent $\left(\mathrm{KC}_{8}\right)$ vs. the metal source in the case of $\mathrm{MoCl}_{5}$. The same crystal phases were obtained, whatever the $\mathrm{K}: \mathrm{MoCl}_{5}$ stoichiometry $(0.5,1$ or 2$)$. A higher proportion of 
carbide was observed when the potassium was introduced in default or in stoichiometric amount. The presence of the same crystallographic phases indicates the reaction of reduction of the metal salt by $\mathrm{KC}_{8}$ does not go through stable species with intermediary oxidation states but directly to the metallic or the metal carbide nanoparticles. As the heat released by the reaction is limited by the reagent in default, whereas the heat capacity is imposed by the whole mixture, the combustion temperature would normally be maximal for a $\mathrm{K}: \mathrm{MCl}_{x}$ ratio of 1. Thermodynamic calculations give an adiabatic temperature of respectively $1100{ }^{\circ} \mathrm{C}$, $1250{ }^{\circ} \mathrm{C}$ and $830{ }^{\circ} \mathrm{C}$ for the $\mathrm{K}: \mathrm{MoCl}_{5}$ ratio of $0.5,1$ and 2 . The reaction with the lowest adiabatic temperature, i.e. corresponding to the potassium introduced in excess, was indeed the one producing the smallest amount of carbide $v s$. the metal $(0)$. 


\subsection{Mechanism proposal}

Reaction initiation. The initiation of the reaction, i.e. the self-ignition of the mixture, depends mainly on two parameters: the nature of the chloride salt and the gas phase. The more reactive compound is $\mathrm{WCl}_{6}$ followed by $\mathrm{MoCl}_{5}, \mathrm{NbCl}_{5}, \mathrm{TaCl}_{5}$ and then $\mathrm{ZrCl}_{4}, \mathrm{HfCl}_{4}, \mathrm{MoCl}_{3}$ (see Video in SI). Under vacuum, only $\mathrm{ZrCl}_{4}, \mathrm{HfCl}_{4}$ and $\mathrm{MoCl}_{3}$ needed heat gun activation, the other precursors self-ignited within a few minutes or during gas evacuation. Under Ar, the required heating increased from $\mathrm{WCl}_{6}$ to $\mathrm{MoCl}_{3}$. Roughly, metal chlorides with high melting points (Table 1, column 4) require a stronger heating, with an exception for $\mathrm{WCl}_{6}$ which is the most reactive but has a higher melting point $\left(275^{\circ} \mathrm{C}\right)$ than $\mathrm{MoCl}_{5}\left(194{ }^{\circ} \mathrm{C}\right), \mathrm{TaCl}_{5}\left(216^{\circ} \mathrm{C}\right)$ and $\mathrm{NbCl}_{5}\left(205^{\circ} \mathrm{C}\right)$. MacKenzie et al. attributed the self-ignition temperature to the lowest temperature at which one of the two reagents undergoes a physical state change. ${ }^{[9]}$ Tungsten hexachloride $\mathrm{WCl}_{6}$ undergoes a crystallographic phase transition $\alpha \rightarrow \beta$ at a lower temperature $\left(177^{\circ} \mathrm{C}\right)$ than the melting point of the second more reactive precursor, $\mathrm{MoCl}_{5}$ $\left(194{ }^{\circ} \mathrm{C}\right)$. The trend mentioned by MacKenzie is therefore in agreement with our observations. Interestingly in our case, even though the trend is respected (including $\mathrm{WCl}_{6}$ if we take into account the solid phase transition), there is no need to attain the actual physical state change temperature to trigger the reaction. We could not explain such a high reactivity with $\mathrm{KC}_{4} / \mathrm{KC}_{8}$. Applying vacuum decreases the melting points of all the chloride salts: we hypothesize this effect is significant enough to explain the higher reactivity under vacuum than in Ar.

Reduction step. In this study, metallic phases were reported for all the metals (Figure 1), the degree of oxidation of the metallic element is then 0. For a series of reactions, the crude was analyzed by PXRD in capillary under argon after reaction but before neutralization with ethanol or water. Potassium chloride $(\mathrm{KCl})$ was systematically detected in high proportions (Figure S18), the reduction of the metal chlorides in metallic or carbide phases is 
therefore allowed by the oxidation of $\mathrm{KC}_{4}$ or $\mathrm{KC}_{8}$ in $\mathrm{K}^{+}$. If alternative pathways exist, they were not detected. EDS measurements on washed samples display systematically the same molar concentration in $\mathrm{K}$ and $\mathrm{Cl}$ elements (Tables S5-7), excluding significant insertion of one of these two elements in the metal-containing nanoparticles, in a bronze phase $\mathrm{K}_{x} \mathrm{WO}_{3}$ for instance. The presence of metallic phases comforts the hypothesis made by the community according to which the solid-state carbide metathesis reactions go along a sequential reduction-recombination pathway and that the metallic state is an intermediate of the reaction (Eq. 3). ${ }^{[26]}$ The carbon element is not directly transferred from $\mathrm{KC}_{4}$ or $\mathrm{KC}_{8}$ to the metal. Most of the nanoparticles formed during this step are supported on the carbon (Scheme 1, step (1)). Different techniques were developed to study the initiation and propagation of SHS. They include electrothermal explosion (ETE), combustion velocity measurements and highly timeresolved XRD ${ }^{[36]}$ Even though they would be of high interest to better study the first steps of the reaction in situ, these techniques are not trivial to implement and fall beyond the scope of this study.

$$
\mathrm{MCl}_{x}+x \mathrm{KC}_{4} \text { or } 8 \rightarrow \mathrm{M}(0)+x \mathrm{KCl}+\text { excess } \mathrm{C} \rightarrow \mathrm{MC} / \mathrm{M}_{2} \mathrm{C}+x \mathrm{KCl}+\text { excess } \mathrm{C}
$$

Carburization step. To the exception of Hf, carbide phases were reported for all metals but in varying proportions depending on the group of the metal and on the process parameters. The reactions with Group VI metals tend to produce more carbides than Group V and Group IV metals and the carbide phase was usually obtained in higher proportions when process parameters favored high temperatures such a fine granularity of the precursors, the presence of a gas phase or a large scale. We also detected traces of $\mathrm{WC}$ in addition of $\mathrm{W}_{2} \mathrm{C}$ on reactions led on large scales between $\mathrm{WCl}_{6}$ and $\mathrm{KC}_{4}$ (Figure $\left.4 \mathrm{H}\right)$. Under thermodynamic control, tungsten monocarbide (WC) is synthesized at higher temperatures than ditungsten carbide $\left(\mathrm{W}_{2} \mathrm{C}\right)$. We therefore suggest all the carbide phases are obtained by carburization of 
the preformed metallic NPs. This carburization corresponds to the diffusion of carbon atoms from the graphite or the acetylene black to the metallic NPs (Scheme 1, step (2)).

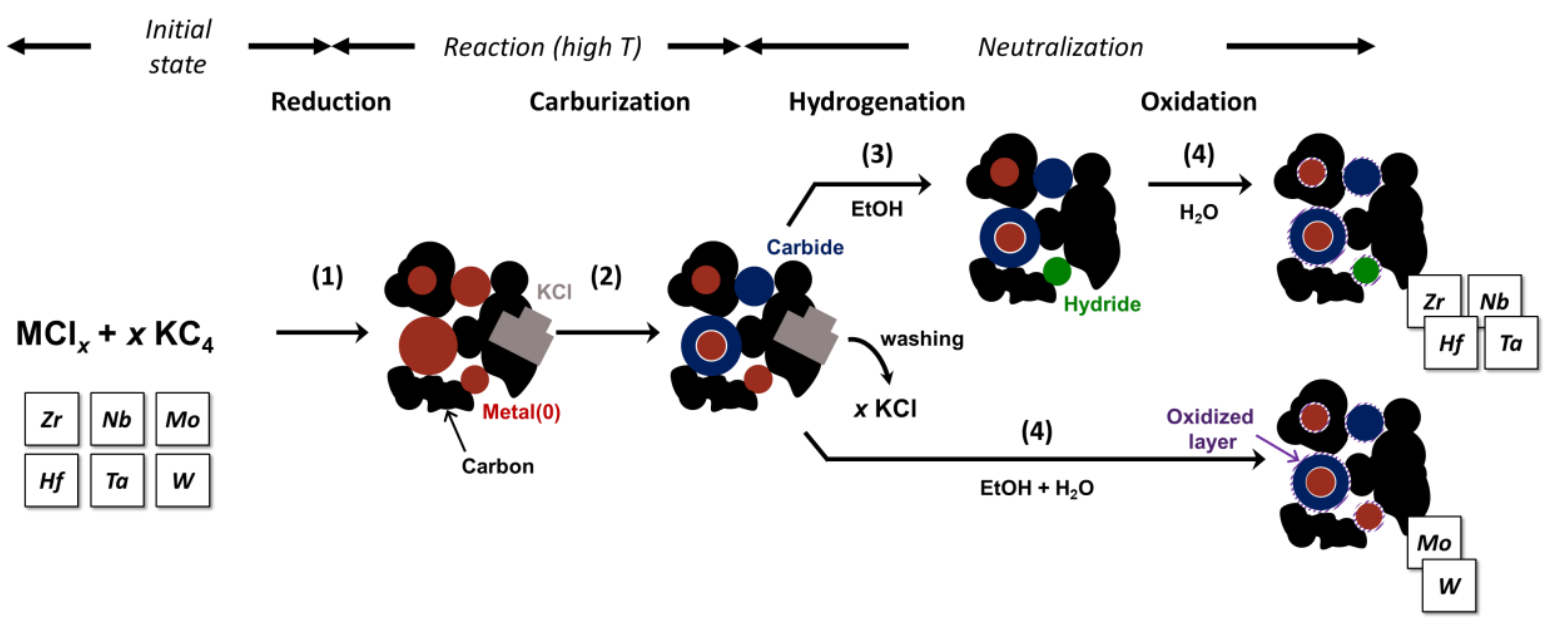

Scheme 1. Proposed reaction mechanism. Top: elements that form metal hydrides, bottom: elements that do not form metal hydrides.

On several samples with $\mathrm{WCl}_{6}$, core-shell structures are observed with TEM (Figure 5A-E). According to the contrast, the core is more electron-rich than the shell. Diffraction fringes appear on STEM micrograph for the core (Figure 5B) and the corresponding distance $(2.2 \AA)$ could correspond to $\mathrm{W}_{2} \mathrm{C}$ or $\mathrm{W}(0)$. It is not possible to discriminate between these two phases because of their close diffraction patterns $\left(2.27 \AA\right.$ for $\mathrm{W}_{2} \mathrm{C}$ and $2.24 \AA$ for $\left.\mathrm{W}(0)\right)$. EDS performed on the different zones reveals that they all contain high amounts of carbon, which was expected considering the presence of graphite in the whole sample, but negligible amounts of oxygen (Figure 5F). Although EDS is not quantitative for light elements, the hypothesis of a tungsten oxide $\left(\mathrm{WO}_{3}\right)$ shell can be excluded. As to the core-shell particles, the shell and the core could not be discriminated by EDS: both contain significant amounts of tungsten. No diffraction fringes could be observed in the shell, preventing a direct phase identification: whether the shell contains a carbide phase or inclusion of tungsten atoms into a carbon shell cannot be decided based on these micrographs. However, as the number of tungsten atom per volume unit slightly decreases when $\mathrm{W}(0)$ is transformed in $\mathrm{W}_{2} \mathrm{C}$, a core- 
shell structure $\mathrm{W} @ \mathrm{~W}_{2} \mathrm{C}$ is consistent with the observed contrast (dark for core, light for shell).

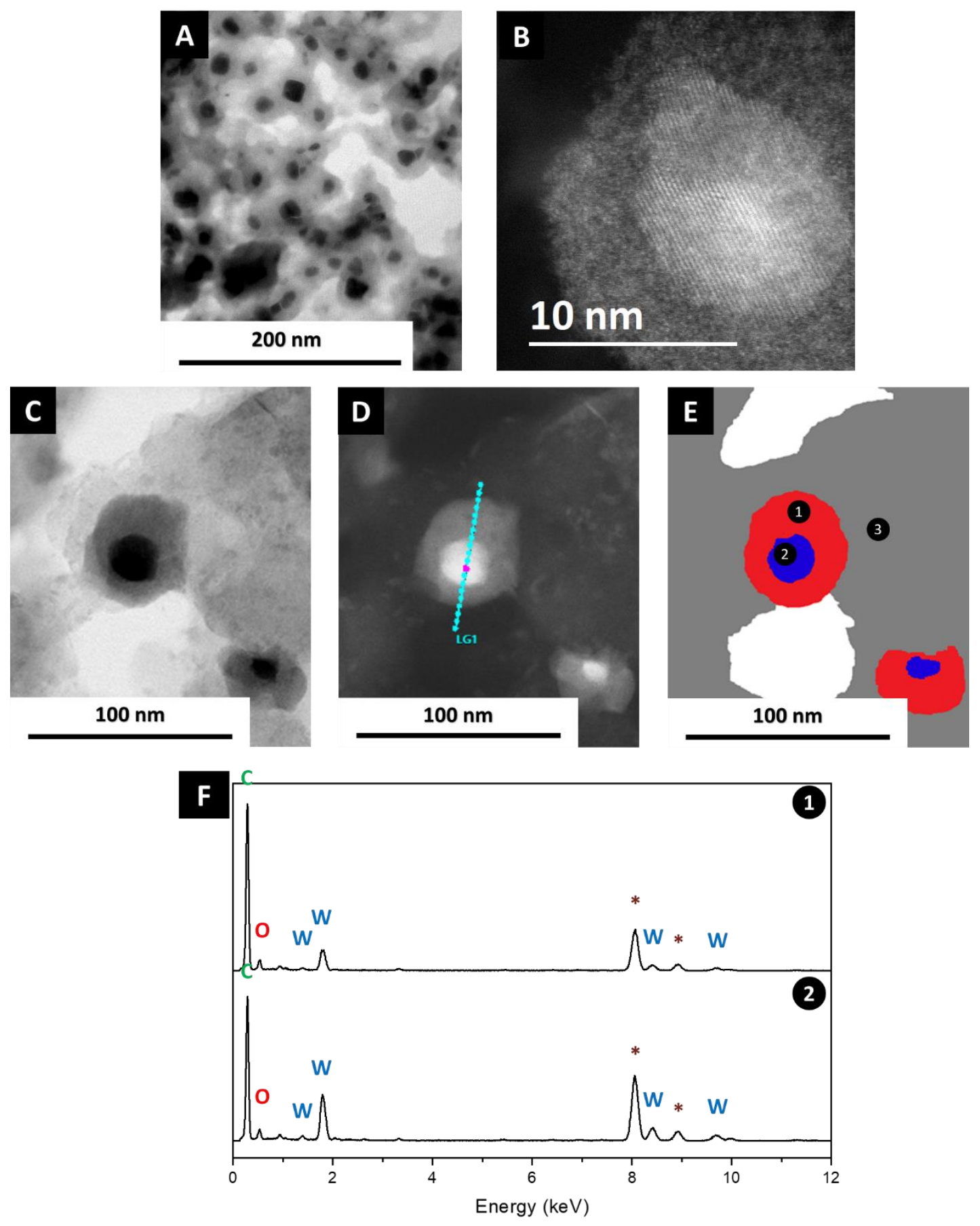

Figure 5. Core-shell particles via the reaction of $\mathrm{WCl}_{6}$ with $\mathrm{KC}_{8}$ under vacuum. A) C) BrightField and B) D) High Angle Annular Dark-Field Scanning Transmission Electron Microscopy of tungsten-containing NPs supported on graphite. E) Scheme of the sample with suggested phases (blue $=$ metallic tungsten, red $=\mathrm{W}_{2} \mathrm{C}$ or carbon with tungsten clusters and grey $=$ graphite). F) EDS spectra of the zones (1) and (2) (the asterisks correspond to $\mathrm{Cu}$, from the EDS anode). 
Hehemann et al. studied the mechanism of carburization of tungsten metal particles by acetylene black into tungsten carbides $\mathrm{WC}$ and $\mathrm{W}_{2} \mathrm{C} .{ }^{[37]}$ The commonly accepted pathway is a two-stage process starting with the formation of ditungsten carbide $\left(\mathrm{W}_{2} \mathrm{C}\right)$ followed by carburization in WC: $\mathrm{W}(0) \rightarrow \mathrm{W}_{2} \mathrm{C} \rightarrow \mathrm{WC}$. Carbon diffuses more rapidly in $\mathrm{W}_{2} \mathrm{C}$ than in WC, the carbon initially in contact with the metallic particle reacts to form a thin outer shell of WC. From this WC shell, metallic tungsten is converted to $\mathrm{W}_{2} \mathrm{C}$. As long as the metallic core has not completely reacted, the WC outer shell does not significantly grow and stays thin. If the complete carburization of $\mathrm{W}(0)$ is not attained, the major phase is thus $\mathrm{W}_{2} \mathrm{C}$. In our study, according to PXRD, the final product is a mixture of the "intermediate" $\mathrm{W}_{2} \mathrm{C}$ and of $\mathrm{W}(0)$ which leads us to hypothesize that $\mathrm{W}(0)$ nanoparticles are not fully carburized. The only partial transformation of the metallic NPs is due to both the brevity of the reaction $(<1 \mathrm{~s})$ and the too low temperatures. All the other studies on similar solid state metathesis reactions comporting tungsten carbides report the WC phase with no formation of the $\mathrm{W}(0)$ phase. However, higher ignition points are reported $\left(>200^{\circ} \mathrm{C}\right)$ and the powder mixture is heated after reaction (at least $1 \mathrm{~h}$ at $500{ }^{\circ} \mathrm{C}$ ) (Table $\mathrm{S} 1$ ). We hypothesize a similar mechanism is operating for other metals, core-shell Mo@ $\mathrm{Mo}_{2} \mathrm{C}$ structures were for instance observed by reaction of a carburizing agent (1-chlorobutane) on metallic NPs. ${ }^{[38]}$

Hydrogenation reaction. One of the major products for reactions with $\mathrm{ZrCl}_{4}, \mathrm{HfCl}_{4}, \mathrm{NbCl}_{5}$ and $\mathrm{TaCl}_{5}$ is the metal hydride (Figure 1 and $\mathrm{S} 3$ ). Due to their electronegativity, early transition metals (Groups IV and V) easily form hydrides. No common metal hydride phases are reported for Mo and $\mathrm{W}$ under standard pressures, i.e. below $1 \mathrm{GPa}{ }^{[39,40]}$ However, one key point of the reduction of metal chlorides with $\mathrm{KC}_{4}$ or $\mathrm{KC}_{8}$ is the theoretical absence of oxygen and hydrogen atoms in the mixture before the neutralization step with EtOH. To elucidate the origin of the metal hydrides $\left(\mathrm{MH}_{y}\right)$, we conducted a series of PXRD in capillary under argon on powders from reactions with $\mathrm{ZrCl}_{4}, \mathrm{NbCl}_{5}$ and $\mathrm{TaCl}_{5}$, before exposure to ethanol or air 
(Figure S18). For the three metals, a metallic phase $(\operatorname{Zr}(0), \mathrm{Nb}(0)$ and $\mathrm{Ta}(0))$ and a hydride phase $\left(\mathrm{ZrH}_{2}, \mathrm{NbH}_{0.8}\right.$ and $\left.\mathrm{TaH}_{0.5}\right)$ are present, the same phases as the ones present after neutralization. Not all the peaks could be attributed for diffractograms in capillary but as these peaks are not present anymore after the washing step, they certainly correspond to air- or water-sensitive compounds. Because there is theoretically no $\mathrm{H}$ atom in the reaction before the neutralization, the hydrogens probably come from impurities in the graphite or acetylene black.

Prolonged bubbling is observed upon addition of ethanol on the crude mixture (neutralization step). It may originate either from the neutralization of potassium, producing thereby $\mathrm{H}_{2}$ gas (Eq. 5), or from the surface oxidation of the metallic nanoparticles. Indeed, NPs of metals such as $\operatorname{Zr}(0), \mathrm{Hf}(0), \mathrm{Nb}(0)$ or $\mathrm{Ta}(0)$ are particularly reactive. PXRD of the samples after neutralization display a decrease of the $\mathrm{M}(0)$ peak and an increase of the $\mathrm{MH}_{y}$ peak (Figure S18A-C). Hydride formation can therefore be explained by hydrogenation of the metallic NPs formed upon reaction and which have not been carburized (Scheme 1, step (3)). Two mechanisms are possible: either ethanol directly reacts with the metallic surface to provide $\mathrm{H}$ atoms and form organic oxidized species (Eq. 4) or ethanol reacts with leftover $\mathrm{KC}_{4}$ or $\mathrm{KC}_{8}$ to produce in situ $\mathrm{H}_{2}$ (Eq. 5) ${ }^{[41]}$ which diffuses in the metal (Eq. 6). This last hypothesis (Eq. $5+6$ ) is less probable as significant amounts of $\mathrm{KC}_{4}$ or $\mathrm{KC}_{8}$ are needed to form the hydrides. For instance, $\mathrm{ZrCl}_{4}$ reacts with 4 equiv. of $\mathrm{KC}_{4}$ to form $\mathrm{Zr}(0)$ and 2 others equiv. of $\mathrm{KC}_{4}$ would be needed to form $\mathrm{ZrH}_{2}$.

$$
\begin{gathered}
y \mathrm{EtOH}+\mathrm{M}(0) \rightarrow \mathrm{MH}_{y}+\text { organic oxidized species } \\
2 \mathrm{EtOH}+2 \mathrm{KC}_{4} \rightarrow 2 \mathrm{EtOK}+\mathrm{H}_{2}+8 \mathrm{C}_{\mathrm{ac}-\mathrm{b}} \\
y / 2 \mathrm{H}_{2}+\mathrm{M}(0) \rightarrow \mathrm{MH}_{y}
\end{gathered}
$$

The exothermicity of the hydrogenation reaction is coherent with the moderate temperature elevation of the Schlenk when the solvent is added. ${ }^{[39]}$ Contrarily to the usual hydride 
syntheses, there is no need for prolonged period of reaction at high temperatures probably because of the small size of the nanoparticles: diffusion of hydrogen atoms in the metal is fast. Figure $\mathrm{S} 18 \mathrm{C}$ shows diffractograms of the reaction of $\mathrm{NbCl}_{5}$ with $5 \mathrm{KC}_{4}$ : the reaction crude under inert atmosphere (Figure S18C, bottom), after exposure to air (Figure S18D, bottom) and after washing (Figure S18C and D, top). A simple exposure to traces of water from atmosphere is enough to start producing hydrides, although metallic phase is still present, whereas there is exclusively metal hydride after the washing step. The distribution of the phases within each NP is still unclear as it could contain metal hydride, metal(0) and metal carbide. In particular, we could not determine if metal(0) detected after the neutralization (Figure $1 \mathrm{~A}, \mathrm{~B}$ for $\mathrm{Zr}$, Hf and Figure $4 \mathrm{E}, \mathrm{N}_{2}$ for $\mathrm{Nb}$ ) was not hydrogenated because it was inaccessible due to an oxide shell or because it was imbedded in the carbon support. In the case of the reaction of $\mathrm{NbCl}_{5}$ with $\mathrm{KC}_{4}$ under $\mathrm{Ar}, \mathrm{Nb}(0)$ was detected but not the hydride (Figure 4E). This may be due to the formation of a carbide shell around the nanoparticles, preventing the solvent and/or $\mathrm{H}_{2}$ to access the metallic part and consequently react with it. This description of the hydrogenation step comforts our choice of discussing together the metallic and hydride phases when we commented the impact of exothermicity on the possible formation of the carbide phase.

Most of the research on metal hydride materials is focused on Group I ( $\mathrm{Li}, \mathrm{Na}, \mathrm{K}$ ), Group II (Be, Mg, Ca), Group X (Ni, Pd, Pt) and Group XIII (B, Al) metals and essentially for hydrogen storage applications, i.e. in dry environments with microparticles. ${ }^{[42]}$ There are therefore few descriptions of transition metal hydride surfaces in solvent such as $\mathrm{H}_{2} \mathrm{O}$ or EtOH. The metal hydride nanoparticles synthesized here were stable over several weeks based on their XRD patterns, however, surface oxidation may occur, acting as a passivation barrier.

Oxidation reaction. In PXRD, crystalline metal oxides were detected both for $\mathrm{ZrCl}_{4}$ and $\mathrm{HfCl}_{4}$ (Figure 1) but not for all the other metals. The diffraction peaks are extremely 
broad, indicating a thin oxide layer at the surface of the NPs. All the XPS results indicate the presence of an oxidized layer but limited to the extreme surface of the NPs (Scheme 1, step (4)). This oxidation is limited by the soft conditions at which it occurs: the neutralization step is done at ambient temperature, under a carpet of $\mathrm{N}_{2}$ and with EtOH. For metals of Group V and VI, as no crystalline oxide phase was detected, we attribute the oxidized species detected by XPS to a surface oxycarbide or to hydroxylated surface metal atoms. XRD allows the detection of crystalline phases and is not suitable to characterize the presence of amorphous ones: amorphous oxides are likely to be present along with crystalline hydrides.

According to the results from electron microscopies and our proposed mechanism, all the obtained phases are mixed at the nanoscale and product purification will be challenging. The present work focused on the synthesis mechanism of the materials. For applications in catalysis, our work already provides synthetic conditions leading to almost pure phases, in particular for $\mathrm{Mo}_{2} \mathrm{C}, \mathrm{W}_{2} \mathrm{C}, \mathrm{TaH}_{0.5}$ and $\mathrm{NbH}_{0.8}$. Furthermore, as to carbide formation, we demonstrated that increasing the scale of the reaction promotes the carburization. Finally, the intimate contact between the nanoparticles and the carbon support should allow a good colloidal stability in liquid phase catalysis, without stabilizer additives, and a good electronic conductivity in electrocatalysis. 


\subsection{Discussion}

Scale up and explosivity in the context of Green Chemistry. If a scale up is envisioned, the natural combustion temperature of the system may differ from the desired one. When temperatures lower than the adiabatic ones are targeted, a common technique consists in diluting the initial mixture with an inert salt, such as $\mathrm{NaCl}$ or $\mathrm{KCl}$, which will act as a heat absorber, due to the salt melting enthalpy. On the contrary, when higher temperatures are targeted, one can surround the reactive powder by another SHS-active mixture, which will liberate heat too when the reaction will be triggered. This last technique is termed "chemical oven" and limits the cooling by heat transfer. Together, these two strategies, inert salt addition and "chemical oven", allow the monitoring of the combustion temperature and therefore the phase speciation. They are more suited to scales larger than the ones used in the present work. ${ }^{[6]}$

At first view, the explosivity of the reaction may be in conflict with the twelfth principle of Green Chemistry calling for safer chemistry procedures. Three aspects must be discussed: the high temperatures reached by the medium, the pyrophoricity of the reagents and the explosivity due to gas dilatation. The first point is inherent to many chemistries and in particular that of refractory compound synthesis: we believe industries are already in capacity to deal with it as large scale applications, i.e. more than 10000 tons per year, are already reported using SHS principle. ${ }^{[6]}$ For the second point, one great advantage of the synthesis is that $\mathrm{KC}_{4}$ and $\mathrm{KC}_{8}$ may be formed in situ from metallic potassium and then mixed with the metal chloride, thereby limiting the need to transport highly reactive compounds. Finally, considering the risk of thermal dilatation of the gases in the closed vessel, we suggest to run the reaction in vacuum if the phase speciation is compatible with such conditions or to connect the vessel to a Schlenk line (or a container of inert gas), which will act as a "pressure buffer". With such precautions, no particular risk is expected while running the experiment. 
Reagent choices. This study is the continuation of works from the $1990 \mathrm{~s}$ using $\mathrm{Al}_{4} \mathrm{C}_{3}$, $\mathrm{CaC}_{2}$ or $\mathrm{SrC}_{2}$ carbides as reducing agents, but with potassium derived compounds $\left(\mathrm{KC}_{4}\right.$ and $\left.\mathrm{KC}_{8}\right) \cdot{ }^{[9,20,26]}$ While the three first ones are carbides stricto sensu (equivalent terms, methide and acetylide, may also be found), $\mathrm{KC}_{4}$ is an impregnation compound without particular known crystallographic structure and $\mathrm{KC}_{8}$ is a Graphite Intercalation Compound (GIC). Although there are a few occurrences of potassium carbide $\mathrm{K}_{2} \mathrm{C}_{2}$ in literature, this compound appears to be much less studied and common than $\mathrm{KC}_{8}$. On the contrary, GICs also include $\mathrm{LiC}_{6}, \mathrm{CaC}_{6}, \mathrm{SrC}_{6}$ and others. Carbides and GICs have undoubtedly different structures and properties but for the study of solid-state metathesis, we considered the comparison was relevant as they have comparable elemental compositions and both present a reductive character. $\mathrm{KC}_{8}$ and $\mathrm{KC}_{4}$ were chosen as they are easily prepared on a gram scale in one step from potassium and graphite at $100{ }^{\circ} \mathrm{C}$ under $\mathrm{Ar}$, which is not the case of $\mathrm{CaC}_{6}$ (metallic calcium melts at $842{ }^{\circ} \mathrm{C}$ vs. $63{ }^{\circ} \mathrm{C}$ for metallic potassium). We thought $\mathrm{KC}_{4}$ and $\mathrm{KC}_{8}$ production is more respectful of the green chemistry principles than $\mathrm{CaC}_{2}$ as this last one is obtained by mixing lime $(\mathrm{CaO})$ and carbon at elevated temperatures with an electric arc furnace, producing carbon monoxide.

We could not determine why the use of $\mathrm{KC}_{4}$ or $\mathrm{KC}_{8}$ allows the ignition to be done at ambient, or close, conditions but this is an obvious energy-saving advantage. A selection of articles reporting the synthesis of metal carbide nanoparticles by SSM is presented in Table S1. The ignition temperatures of the reactions reported in our present work are between room temperature and $75^{\circ} \mathrm{C}$, while the similar reactions using calcium carbide $\mathrm{CaC}_{2}$ as the reducing agent was initiated at $200{ }^{\circ} \mathrm{C}$ at the lowest and necessitates a heating at $500{ }^{\circ} \mathrm{C}$ for at least one hour to fully crystallize the products. ${ }^{[10]}$ To the best of our knowledge, all the other carbide syntheses via the SSM route have ignition temperatures of $200{ }^{\circ} \mathrm{C}$ at least. Ignition at room temperatures are reported but for other families of materials, such as nitrides or 
sulfides. ${ }^{[6]}$ We hypothesize the combination of the low ignition temperatures $\left(<75^{\circ} \mathrm{C}\right)$ and the absence of heating after reaction explain the unexpected production of hydrides $\left(\mathrm{ZrH}_{2}\right.$, $\mathrm{HfH}_{1.7}, \mathrm{NbH}_{0.8}$ and $\mathrm{TaH}_{0.5}$ ) via metallic particles, never reported for SSM. These hydride phases do not strico sensu result from the SSM as they are the products of the hydrogenation of small metallic particles. However, they are among the smallest metal hydride NPs reported as these phases are usually synthesized by metal microparticles hydrogenation with $\mathrm{H}_{2}$.

We already mentioned the use of metal oxides as precursors, instead of metal chlorides. Although the substitution of the metal chloride by a similar metal oxide would have been of high interest, in particular in terms of green chemistry (simpler reagents, not air or water sensitive, no use of $\mathrm{Cl}$ ), we demonstrated the MSSM was not possible when the reducing agent is potassium for thermodynamic reasons. On the contrary, MSSM with $\mathrm{CaC}_{2}$ and metal oxides was successfully reported by Nartowski et al. in the case of $\mathrm{V}_{2} \mathrm{O}_{3}, \mathrm{Nb}_{2} \mathrm{O}_{5}$, $\mathrm{Ta}_{2} \mathrm{O}_{5}, \mathrm{MoO}_{3}$ and others (see Table S1, Ref [4]). The authors nonetheless indicated the mixtures ignited at much higher temperatures than with metal chlorides $\left(480-650{ }^{\circ} \mathrm{C}\right.$ for MSSM vs. $200-350{ }^{\circ} \mathrm{C}$ for SSM) and that there was no thermal flash at the ignition. They noticed instead a darkening of the powder over 20 seconds. This may be interpreted as a lower exothermicity. Moreover, a longer annealing step was needed for MSSM $\left(12 \mathrm{~h}\right.$ at $1000{ }^{\circ} \mathrm{C}$ instead of $1 \mathrm{~h}$ at $500{ }^{\circ} \mathrm{C}$ ). All these observations are coherent with our thermodynamic calculations. Indeed, among the metals studied both in this article and by Nartowski et al. ( Nb, Ta, Mo, W), the theoretical enthalpies of reaction are between $-144 \mathrm{~kJ} / \mathrm{mol}$ and $+282 \mathrm{~kJ} / \mathrm{mol}$ for MSSM with $\mathrm{KC}_{8}$ (no reaction), between $-974 \mathrm{~kJ} / \mathrm{mol}$ and $-409 \mathrm{~kJ} / \mathrm{mol}$ for MSSM with $\mathrm{CaC}_{2}$ (moderate reaction), between $-1305 \mathrm{~kJ} / \mathrm{mol}$ and $-707 \mathrm{~kJ} / \mathrm{mol}$ for $\mathrm{SSM}$ with $\mathrm{CaC}_{2}$ (explosive reaction) and between $-1826 \mathrm{~kJ} / \mathrm{mol}$ and $-817 \mathrm{~kJ} / \mathrm{mol}$ for $\mathrm{SSM}$ with $\mathrm{KC}_{8}$ (explosive reaction) (data displayed in Table S3). 
Scope of application. Similar works on SSM of metal carbide nanoparticles report attempts to use metal chlorides of late transition (beyond column VI) but all failed to produce carbides. This systematic result was named the "chromium enigma". One advanced explanation is the poor stability of the corresponding metal carbides with high temperature in comparison with early transition metals: the carbides are formed but immediately melt or degrade. We present in Table 2 the melting temperatures of the majority of the stable carbide phases of transition metals in relation with the adiabatic temperature for a hypothetical reaction between $\mathrm{KC}_{8}$ and the corresponding metal chloride. First, it appears the melting temperatures of the carbides of all the metals studied in this work and from a previous study of our group $^{[20]}(\mathrm{Ti}, \mathrm{Zr}, \mathrm{Hf}, \mathrm{V}, \mathrm{Nb}, \mathrm{Ta}, \mathrm{Mo}, \mathrm{W}$ ) are above the boiling point of $\mathrm{KCl}$ and thereby above the adiabatic temperature, to the noticeable exception of $\mathrm{MoC}\left(1220^{\circ} \mathrm{C}\right)$ which was not obtained in our study. Then, for scandium and yttrium carbides, the melting temperatures (respectively $1864{ }^{\circ} \mathrm{C}$ and $1645^{\circ} \mathrm{C}$ ) are well above the adiabatic temperatures (respectively $520^{\circ} \mathrm{C}$ and $460{ }^{\circ} \mathrm{C}$ ) but there are doubts about the possibility to ignite the reaction considering the low enthalpies of reaction for $\mathrm{SSM}$ between $\mathrm{ScCl}_{3}$ or $\mathrm{YCl}_{3}$ and $\mathrm{KC}_{8}$ (respectively $-272 \mathrm{~kJ} / \mathrm{mol}$ and $-235 \mathrm{~kJ} / \mathrm{mol}$, see Table S3). These enthalpies of reaction are comparable with the ones obtained for MSSM reactions with $\mathrm{KC}_{8}$ and which were unsuccessful. Lanthanide and actinide elements, to the exception of Pm, form at least one stable carbide, the most common ones being $\mathrm{M}_{2} \mathrm{C}_{3}$ and $\mathrm{MC}_{2} \cdot{ }^{[43]} \mathrm{M}_{2} \mathrm{C}_{3}$ carbides are generally stable up to $c a .1500{ }^{\circ} \mathrm{C}$ while $\mathrm{MC}_{2}$ decomposes at $c a .2200{ }^{\circ} \mathrm{C}$. The limiting point here seems to be the same as for Sc and Y: the low enthalpy of reaction. The example of $\mathrm{LaCl}_{3}$, expected to be representative of all lanthanides, leads to a reaction enthalpy of only $-147 \mathrm{~kJ} / \mathrm{mol}$. Concerning $\mathrm{Cr}$ and $\mathrm{Mn}$, the situation is in the middle: the degradation temperatures are around the boiling point of $\mathrm{KCl}\left(1500{ }^{\circ} \mathrm{C}\right)$ and therefore technically accessible although the adiabatic temperature is systematically below. Nartowski et al. reported the synthesis of $\mathrm{Cr}_{3} \mathrm{C}_{2}$ when 
using $\mathrm{CaC}_{2}{ }^{[26]}$ Iron presents several carbide phases between $\mathrm{Fe}_{2} \mathrm{C}$ and $\mathrm{Fe}_{4} \mathrm{C}$, all metastable. The only relevant one here is the cementite $\mathrm{Fe}_{3} \mathrm{C}$ whose degradation is particularly slow, literature indicating a limit degradation temperature of $1252{ }^{\circ} \mathrm{C} .{ }^{[44]}$ Cobalt presents two main metastable carbide phases, $\mathrm{CoC}_{2}$ and $\mathrm{CoC}_{3}$, for which the literature defines a degradation temperature of respectively $469^{\circ} \mathrm{C}$ and $491^{\circ} \mathrm{C} .{ }^{[45]}$ Nickel presents only one metastable carbide phase, $\mathrm{Ni}_{3} \mathrm{C}$. The compound does not melt but is decomposed into $\mathrm{Ni}(0)$ and $\mathrm{C}$. As the phase is metastable, there is no defined degradation temperature but the usual range of degradation temperatures is $300-500{ }^{\circ} \mathrm{C} .{ }^{[46]}$ Nickel and cobalt carbides would be undoubtedly degraded if formed during the SSM but the case of iron carbide is borderline. There is up to now no mention of a common carbide phase for $\mathrm{Ru}, \mathrm{Rh}, \mathrm{Pd}, \mathrm{Re}, \mathrm{Os}$, Ir and Pt. Metals of column XI ( $\mathrm{Cu}, \mathrm{Ag}, \mathrm{Au})$ form explosive acetylide $\mathrm{M}_{2} \mathrm{C}_{2}$ and those of column XII ( $\mathrm{Zn}, \mathrm{Cd}$, $\mathrm{Hg}$ ) form not well characterized carbides, these compounds are therefore beyond the scope of this work. 


\begin{tabular}{|c|c|c|c|c|c|c|c|}
\hline Metal & Carbide & $\begin{array}{c}\text { Melting } \\
\text { temperature }\end{array}$ & $\begin{array}{c}\text { Adiabatic } \\
\text { temperature }\end{array}$ & Metal & Carbide & $\begin{array}{c}\text { Melting } \\
\text { temperature }\end{array}$ & $\begin{array}{c}\text { Adiabatic } \\
\text { temperature }\end{array}$ \\
\hline \multirow{2}{*}{$\mathrm{Sc}$} & $\mathrm{ScC}$ & $2270^{\circ} \mathrm{C}$ & \multirow{2}{*}{$\begin{array}{l}520^{\circ} \mathrm{C} \\
\left(\mathrm{ScCl}_{3}\right)\end{array}$} & \multirow{3}{*}{$\mathrm{Cr}$} & $\mathrm{Cr}_{3} \mathrm{C}_{2}$ & $1811^{\circ} \mathrm{C}$ & \multirow{3}{*}{$\begin{array}{l}930{ }^{\circ} \mathrm{C} \\
\left(\mathrm{CrCl}_{3}\right)\end{array}$} \\
\hline & $\mathrm{Sc}_{4} \mathrm{C}_{3}$ & $1864^{\circ} \mathrm{C}$ & & & $\mathrm{Cr}_{7} \mathrm{C}_{3}$ & $1766^{\circ} \mathrm{C}$ & \\
\hline \multirow{2}{*}{ Y } & $\mathrm{YC}_{2}$ & $2415^{\circ} \mathrm{C}$ & \multirow{2}{*}{$\begin{array}{l}460^{\circ} \mathrm{C} \\
\left(\mathrm{YCl}_{3}\right)\end{array}$} & & $\mathrm{Cr}_{23} \mathrm{C}_{6}$ & $1576^{\circ} \mathrm{C}$ & \\
\hline & $\mathrm{Y}_{2} \mathrm{C}_{3}$ & $1645^{\circ} \mathrm{C}$ & & \multirow{2}{*}{ Mo } & $\mathrm{MoC}$ & $1220^{\circ} \mathrm{C}$ & \multirow{2}{*}{$\begin{array}{l}1250{ }^{\circ} \mathrm{C} \\
\left(\mathrm{MoCl}_{5}\right)\end{array}$} \\
\hline \multirow{2}{*}{$\mathrm{La}$} & $\mathrm{LaC}_{2}$ & $2360^{\circ} \mathrm{C}$ & \multirow{2}{*}{$\begin{array}{l}320{ }^{\circ} \mathrm{C} \\
\left(\mathrm{LaCl}_{3}\right)\end{array}$} & & $\mathrm{Mo}_{2} \mathrm{C}$ & $2605^{\circ} \mathrm{C}$ & \\
\hline & $\mathrm{La}_{2} \mathrm{C}_{3}$ & $1415^{\circ} \mathrm{C}$ & & \multirow{2}{*}{ W } & WC & $2785^{\circ} \mathrm{C}$ & \multirow{2}{*}{$\begin{array}{c}1280{ }^{\circ} \mathrm{C} \\
\left(\mathrm{WCl}_{6}\right)\end{array}$} \\
\hline $\mathrm{Ti}$ & $\mathrm{TiC}$ & $3067^{\circ} \mathrm{C}$ & $\begin{array}{l}770^{\circ} \mathrm{C} \\
\left(\mathrm{TiCl}_{3}\right)\end{array}$ & & $\mathrm{W}_{2} \mathrm{C}$ & $2785^{\circ} \mathrm{C}$ & \\
\hline $\mathrm{Zr}$ & $\mathrm{ZrC}$ & $3445^{\circ} \mathrm{C}$ & $\begin{array}{l}770^{\circ} \mathrm{C} \\
\left(\mathrm{ZrCl}_{4}\right)\end{array}$ & \multirow{4}{*}{$\mathrm{Mn}$} & $\mathrm{Mn}_{7} \mathrm{C}_{3}$ & $1333^{\circ} \mathrm{C}$ & \multirow{4}{*}{$\begin{array}{c}770{ }^{\circ} \mathrm{C} \\
\left(\mathrm{MnCl}_{2}\right)\end{array}$} \\
\hline Hf & HfC & $3928^{\circ} \mathrm{C}$ & $\begin{array}{l}770^{\circ} \mathrm{C} \\
\left(\mathrm{HfCl}_{4}\right)\end{array}$ & & $\mathrm{Mn}_{5} \mathrm{C}_{2}$ & $1171^{\circ} \mathrm{C}$ & \\
\hline \multirow{3}{*}{$\mathrm{V}$} & VC & $2656^{\circ} \mathrm{C}$ & \multirow{3}{*}{$\begin{array}{l}900^{\circ} \mathrm{C} \\
\left(\mathrm{VCl}_{3}\right)\end{array}$} & & $\mathrm{Mn}_{3} \mathrm{C}$ & $1052^{\circ} \mathrm{C}$ & \\
\hline & $\mathrm{V}_{8} \mathrm{C}_{7}$ & $2650^{\circ} \mathrm{C}$ & & & $\mathrm{Mn}_{23} \mathrm{C}_{6}$ & $1034^{\circ} \mathrm{C}$ & \\
\hline & $\mathrm{V}_{2} \mathrm{C}$ & $2191{ }^{\circ} \mathrm{C}$ & & $\mathrm{Fe}$ & $\mathrm{Fe}_{3} \mathrm{C}$ & $1252{ }^{\circ} \mathrm{C}(\mathrm{d})$ & $\begin{array}{c}1140{ }^{\circ} \mathrm{C} \\
\left(\mathrm{FeCl}_{3}\right)\end{array}$ \\
\hline \multirow{2}{*}{$\mathrm{Nb}$} & $\mathrm{NbC}$ & $3608^{\circ} \mathrm{C}$ & \multirow{2}{*}{$\begin{array}{l}1040{ }^{\circ} \mathrm{C} \\
\left(\mathrm{NbCl}_{5}\right)\end{array}$} & \multirow{2}{*}{ Co } & $\mathrm{Co}_{2} \mathrm{C}$ & $469^{\circ} \mathrm{C}(\mathrm{d})$ & \multirow{2}{*}{$\begin{array}{l}1040^{\circ} \mathrm{C} \\
\left(\mathrm{CoCl}_{2}\right)\end{array}$} \\
\hline & $\mathrm{Nb}_{2} \mathrm{C}$ & $2504^{\circ} \mathrm{C}$ & & & $\mathrm{Co}_{3} \mathrm{C}$ & $491{ }^{\circ} \mathrm{C}(\mathrm{d})$ & \\
\hline \multirow{2}{*}{$\mathrm{Ta}$} & $\mathrm{TaC}$ & $3965^{\circ} \mathrm{C}$ & \multirow{2}{*}{$\begin{array}{c}1000^{\circ} \mathrm{C} \\
\left(\mathrm{TaCl}_{5}\right)\end{array}$} & $\mathrm{Ni}$ & $\mathrm{Ni}_{3} \mathrm{C}$ & $\begin{array}{c}300-500{ }^{\circ} \mathrm{C} \\
\text { (d) }\end{array}$ & $\begin{array}{c}1050^{\circ} \mathrm{C} \\
\left(\mathrm{NiCl}_{2}\right)\end{array}$ \\
\hline & $\mathrm{Ta}_{2} \mathrm{C}$ & $3330{ }^{\circ} \mathrm{C}$ & & & & & \\
\hline
\end{tabular}

Table 2. Melting temperatures of all common carbide phases of transition metals and adiabatic temperature for a hypothetical SSM reaction between $\mathrm{KC}_{8}$ and the different chloride salts. $\mathrm{Fe}$, $\mathrm{Co}$ and $\mathrm{Ni}$ developing only metastable carbide phases, the decomposition temperatures are indicated instead of the melting temperatures. Data are taken from references $[25,47,48]$. 


\section{Conclusion}

We demonstrated the possible use of $\mathrm{KC}_{4}$ and $\mathrm{KC}_{8}$ to produce a variety of carbon-supported nanoparticles (metal(0), carbide, hydride) derived from early transition metals $(\mathrm{Zr}, \mathrm{Hf}, \mathrm{Nb}$, Ta, Mo and W). We showed the possibility to partially modify the combustion temperature and therefore the phase speciation of the reaction by playing on several process parameters. This is particularly interesting as the usual parameters used in chemistry such as the concentration, the reaction temperature and the reaction time are not relevant for solid-state metathesis reactions. Furthermore, this study of the process parameters resulted in a proposed mechanism in four steps: reduction, carburization, hydrogenation and surface oxidation. Using thermodynamic considerations, we demonstrated that the simplest reagents were used and we delineated the scope of this process in terms of reachable compounds. In comparison to the state of the art, our process presents significant gains in energy while preserving the scalability, the versatility, the atom economy and the absence of toxic wastes.

\section{Experimental section}

Synthesis of nanoparticles: The synthesis was adapted from a previous paper. ${ }^{[20]}$ In a Schlenk tube in the glovebox, $100 \mathrm{mg}$ of $\mathrm{KC}_{4}(1.15 \mathrm{mmol}, 1$ equiv. $)$ were mixed with stoichiometric amounts of metal chloride $\mathrm{MCl}_{x}(1.15 / \mathrm{x} \mathrm{mmol}, 1 / \mathrm{x}$ equiv.) by gentle hand-shaking [caution: the mixture may explode] and the Schlenk tube was taken out of the glovebox. The gas phase was eventually removed or changed with $\mathrm{N}_{2}$. The reaction was initiated by gentle heating with a heat gun. Once the reaction is over, the tube was let to cool down to room temperature and then refilled with $\mathrm{N}_{2}$. The solid was neutralized by careful addition of ethanol $(10 \mathrm{~mL})$ and subsequent addition of water $(20 \mathrm{~mL})$. The mixture was shaken and eventually sonicated before being centrifuged $\left(4,000 \mathrm{rpm}, 10 \mathrm{~min}, 20^{\circ} \mathrm{C}\right)$. The supernatant was removed and the black solid was let to dry at air. The supernatant may still have a colour corresponding to a 
leftover of the metal chloride (blue for $\mathrm{WCl}_{6}$, brown for $\mathrm{MoCl}_{5}$ and grey for the others). The reaction is similar with $\mathrm{KC}_{8}(155 \mathrm{mg}, 1.15 \mathrm{mmol}$, 1 equiv.).

Synthesis of $K C_{4}$ and $K C_{8}$ : the protocols are detailed in the supplementary information file.

Characterizations: details regarding XRD, TEM, XPS and XANES are provided in the supplementary information file.

\section{Authors biographies}

Mr. Rémi F. André obtained his MSc. in 2017 from ESPCI Paris, PSL Université, and received an MPhil in 2018 in Supramolecular Chemistry from Cambridge University, UK. In 2018, he started his $\mathrm{PhD}$ at the Laboratoire de Chimie de la Matière Condensée de Paris (LCMCP), associated with Sorbonne Université and Collège de France. His research interests focus on nanoparticle syntheses and colloidal catalysis.

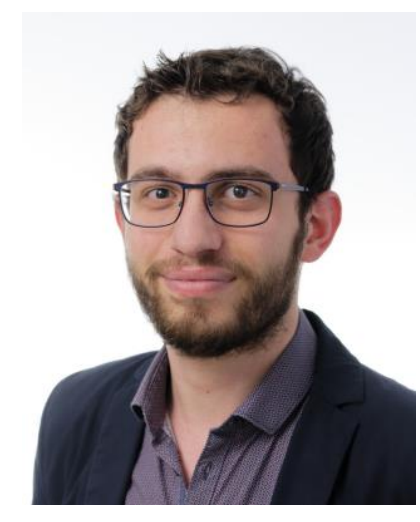

Dr. Florian D'Accriscio obtained his PhD in 2017 from Université Paul Sabatier, Toulouse. From 2017 to 2018, he was a post-doctoral fellow in Laboratoire Chimie de la Matière Condensée, UPMC, Paris. In 2020, he joined Enwires, a start-up producing Si-based composite for Li-ion battery, and is now R\&D Director. 


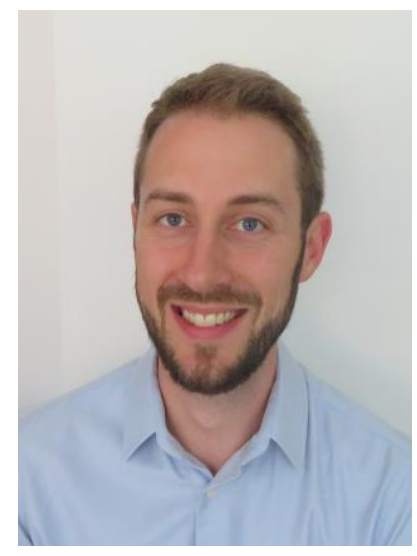

Dr. Alexy P. Freitas graduated from Ecole Normale Supérieure Ulm in 2015. He then obtained his $\mathrm{PhD}$ in 2019 from Ecole polytechnique, and was a post-doctoral fellow in Laboratoire de Chimie de la Matière Condensée de Paris (LCMCP), at Sorbonne Université, Paris.

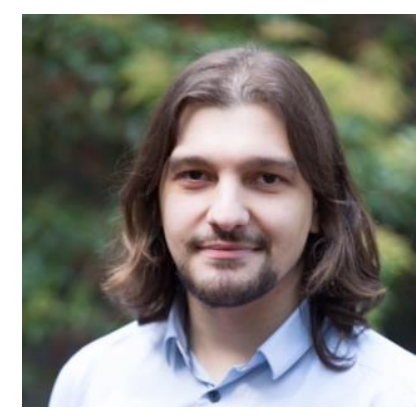

Mr. Guillaume Crochet obtained his MSc. in 2018 from Sorbonne Université, Paris. In 2018, he started his $\mathrm{PhD}$ at the Laboratoire de Chimie de la Matière Condensée de Paris (LCMCP), associated with Sorbonne Université and Collège de France.

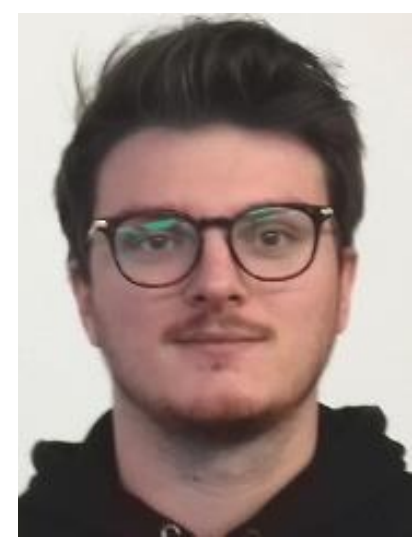


Dr. Corinne Bouillet obtained her $\mathrm{PhD}$ in Materials Science in 1993 from Université de Lille. After one year as post-doctoral fellow at IHP (Institute of semiconductor physics), Franfurt/Oder, Germany, she joined CNRS as a research engineer in Institut de Physique et Chimie des Matériaux de Strasbourg (IPCMS), associated with Université de Strasbourg.

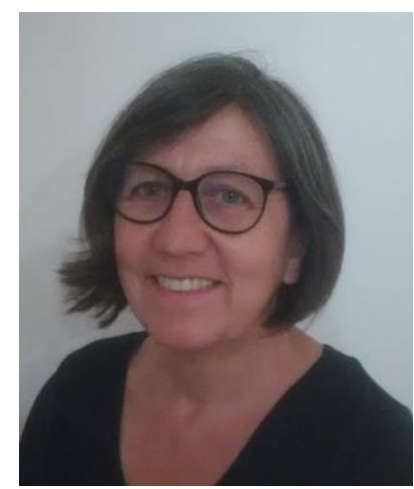

Dr. Mounib Bahri has received his Master's Degree (2012) and his PhD (2016) in Physics from Paris-Saclay University, Orsay, France. After his $\mathrm{PhD}$, he joined IPCMS-CNRS laboratory in Strasbourg as a post-doctoral researcher for four years. He is currently a Senior Research Specialist at the Albert Crewe Centre for Electron Microscopy at the University of Liverpool.

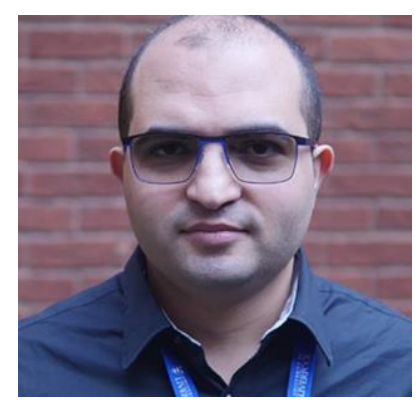

Prof. Ovidiu Ersen obtained his PhD in 2001 from Louis Pasteur University, Strasbourg, France. In 2003, he joined University of Strasbourg as an associate professor in Physics in Institut de Physique et Chimie des Matériaux de Strasbourg (IPCMS), associated with CNRS. Since 2002, he is a Full Professor in the same university and was also affiliated to Institut Universitaire de France from 2014 to 2019. 


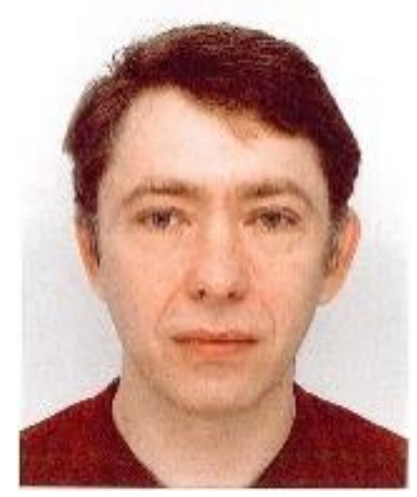

Prof. Clément Sanchez is Emeritus Professor at the Collège de France chair of the Chemistry of Hybrid Materials and Professor at the Institut of Advanved Studies of Strasbourg. He received an engineer degree from l'École nationale supérieure de chimie de Paris in 1978 and a "thèse d'État" $(\mathrm{PhD})$ in physical chemistry from the University of Paris VI in 1981. He did a postdoctoral work at the University of California, Berkeley. He is specialized in the field of nanochemistry of nanostructured porous and non-porous transition metal oxide based gels and porous and non-porous hybrid organic inorganic materials shaped as monoliths, microspheres and films.

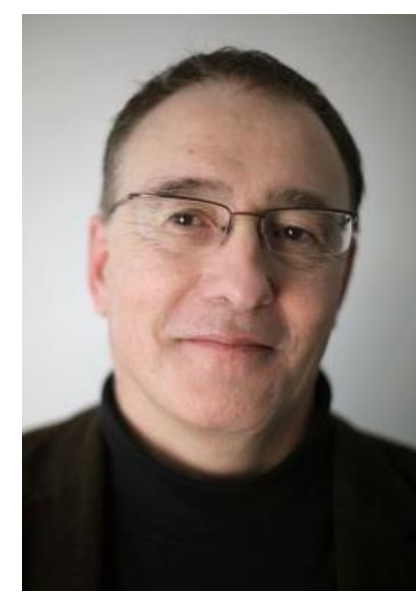

Dr. Sophie Carenco obtained her PhD in 2011 from UPMC, Paris. From 2012 to 2013, she was a post-doctoral fellow at Lawrence Berkeley National Lab in California. In 2014, she joined CNRS as a researcher in Laboratoire de Chimie de la Matière Condensée de Paris 
(LCMCP), associated with Sorbonne Université and Collège de France. In 2017, she was awarded an ERC Starting grant to work in the field of nanochemistry.

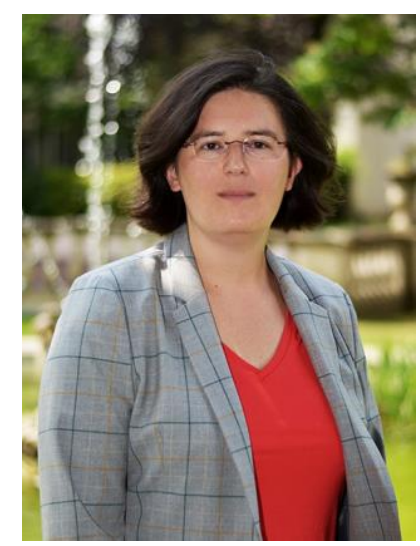




\section{Supporting Information}

General procedures, Materials and methods, Supplementary data from the literature, photos and snapshots of videos, thermodynamic data and calculations, additional powder XRD, TEM, SEM, EDX and XPS.

\section{Author contributions}

R. F. A. conducted the syntheses, the XRD and TEM data treatment and the thermodynamic calculations. F. D. A., G. C. and C. S. participated to the project conception and the preliminary data, including synthesis and characterization. A. P. F. performed and treated the XPS and XAS characterizations. C. U., M. B. and O. E. performed the HRTEM experiments. R. F. A. and S. C. conceived the project and co-wrote the manuscript, S. C. spearheading it. All authors approved the final version of the manuscript.

\section{Conflict of interest}

The authors declare no conflict of interest.

\section{Acknowledgements}

This project has received funding from the European Research Council (ERC) under the European Union's Horizon 2020 research and innovation programme (Grant agreement No. 758480). This work was supported by Sorbonne Université, CNRS and the Collège de France. F. D. A. thanks the Fondation du Collège de France for financial support. The audiovisual service of CNRS and Philippe Arson are acknowledged for the videos. Christophe Méthivier and Antoine Miche, from LRS, are acknowledged for the XPS measurements. Capucine Sassoye, from LCMCP, is acknowledged for her help for PXRD in capillary. This work was supported by a public grant overseen by the French National Research Agency (ANR) as part of the "Investissements d'Avenir" program (reference: ANR 10-EQPX-0045). We acknowledge the ROCK beamline and Valérie Briois at Synchrotron SOLEIL for beamtime (proposal 20191566) for XAS measurements. 


\section{References}

[1] S. T. Oyama, Catal. Today 1992, 15, 179-200.

[2] Y. Zhong, X. Xia, F. Shi, J. Zhan, J. Tu, H. J. Fan, Adv. Sci. 2016, 3, 1500286.

[3] H. H. Hwu, J. G. Chen, Chem. Rev. 2005, 105, 185-212.

[4] R. B. Levy, M. Boudart, Science. 1973, 181, 547-549.

[5] S. V. Ushakov, A. Navrotsky, Q.-J. Hong, A. van de Walle, Materials (Basel). 2019, $12,2728$.

[6] A. G. Merzhanov, J. Mater. Chem. 2004, 14, 1779.

[7] J. B. Wiley, R. B. Kaner, Science. 1992, 255, 1093-1097.

[8] H. C. Yi, J. J. Moore, J. Mater. Sci. 1990, 25, 1159-1168.

[9] A. M. Nartowski, I. P. Parkin, A. J. Craven, M. MacKenzie, Adv. Mater. 1998, 10, 805-808

[10] A. M. Nartowski, I. P. Parkin, M. MacKenzie, A. J. Craven, I. MacLeod, J. Mater. Chem. 1999, 9, 1275-1281.

[11] I. P. Parkin, Chem. Soc. Rev. 1996, 25, 199-207.

[12] H.-J. Meyer, Dalt. Trans. 2010, 39, 5973.

[13] L. Rao, E. G. Gillan, R. B. Kaner, J. Mater. Res. 1995, 10, 353-361.

[14] J. C. Fitzmaurice, A. Hector, I. P. Parkin, Polyhedron 1993, 12, 1295-1300.

[15] B. Song, J. K. Jian, G. Wang, M. Lei, Y. P. Xu, X. L. Chen, Chem. Mater. 2007, 19, $1497-1502$

[16] J. L. O’Loughlin, C. H. Wallace, M. S. Knox, R. B. Kaner, Inorg. Chem. 2001, 40, $2240-2245$.

[17] A. M. Nartowski, I. P. Parkin, Polyhedron 2002, 21, 187-191.

[18] R. F. Jarvis, R. M. Jacubinas, R. B. Kaner, Inorg. Chem. 2000, 39, 3243-3246. 
[19] P. R. Bonneau, R. F. Jarvis, R. B. Kaner, Nature 1991, 349, 510-512.

[20] D. Ressnig, S. Moldovan, O. Ersen, P. Beaunier, D. Portehault, C. Sanchez, S. Carenco, Chem. Commun. 2016, 52, 9546-9549.

[21] A. M. Nartowski, I. P. Parkin, M. Mackenzie, A. J. Craven, J. Mater. Chem. 2001, 11, $3116-3119$.

[22] K. Fredenhagen, G. Cadenbach, Zeitschrift fur Anorg. und Allg. Chemie 1926, 158, $249-263$.

[23] D. E. Bergbreiter, J. M. Killough, J. Am. Chem. Soc. 1978, 100, 2126-2134.

[24] J.-M. Lalancette, G. Rollin, P. Dumas, Can. J. Chem. 1972, 50, 3058-3062.

[25] H. Okamoto, M. E. Schlesinger, E. M. Mueller, Eds. , Alloy Phase Diagrams, ASM International, 2016.

[26] A. M. Nartowski, I. P. Parkin, M. MacKenzie, A. J. Craven, I. MacLeod, J. Mater. Chem. 1999, 9, 1275-1281.

[27] M. Cuppari, S. Santos, Metals (Basel). 2016, 6, 250.

[28] A. S. Kurlov, A. I. Gusev, Inorg. Mater. 2006, 42, 121-127.

[29] D. D. Sarma, P. K. Santra, S. Mukherjee, A. Nag, Chem. Mater. 2013, 25, 1222-1232.

[30] J. S. Lee, J. E. Yie, Korean J. Chem. Eng. 1991, 8, 164-167.

[31] C. He, J. Tao, RSC Adv. 2016, 6, 9240-9246.

[32] P. Vanýsek, in CRC Handb. Chem. Physics, 93rd Ed., CRC, Boca Raton, FL, 2012, pp. $5-80 / 89$.

[33] M. W. Chase, NIST-JANAF Thermochemical Tables, 4th Edition, 1998.

[34] J. C. Taylor, P. W. Wilson, Acta Crystallogr. Sect. B Struct. Crystallogr. Cryst. Chem. 1974, 30, 1216-1220.

[35] G. Mühlbauer, G. Kremser, A. Bock, J. Weidow, W.-D. Schubert, Int. J. Refract. Met. Hard Mater. 2018, 72, 141-148. 
[36] A. S. Mukasyan, C. E. Shuck, Int. J. Self-Propagating High-Temperature Synth. 2017, $26,145-165$.

[37] L. V. McCarty, R. Donelson, R. f. Hehemann, Metall. Trans. A 1991, 18, 969-974.

[38] C.-H. Chien, P.-S. Sheng, C.-H. Wang, C.-H. Huang, H.-K. Lin, C.-Y. Lee, H.-T. Chiu, Mater. Lett. 2007, 61, 3593-3596.

[39] K. Young, in Ref. Modul. Chem. Mol. Sci. Chem. Eng., Elsevier, 2018, pp. 1-23.

[40] M. A. Kuzovnikov, H. Meng, M. Tkacz, J. Alloys Compd. 2017, 694, 51-54.

[41] R. Schlögl, H. P. Boehm, Carbon N. Y. 1984, 22, 341-349.

[42] B. Sakintuna, F. Lamaridarkrim, M. Hirscher, Int. J. Hydrogen Energy 2007, 32, 11211140.

[43] K. A. Gschneidner, F. W. Calderwood, Bull. Alloy Phase Diagrams 1986, 7, 421-436.

[44] H. Okamoto, J. Phase Equilibria 1992, 13, 543-565.

[45] K. Ishida, T. Nishizawa, J. Phase Equilibria 1991, 12, 417-424.

[46] B. C. Bayer, D. A. Bosworth, F. B. Michaelis, R. Blume, G. Habler, R. Abart, R. S. Weatherup, P. R. Kidambi, J. J. Baumberg, A. Knop-Gericke, R. Schloegl, C. Baehtz, Z. H. Barber, J. C. Meyer, S. Hofmann, J. Phys. Chem. C 2016, 120, 22571-22584.

[47] S. R. Shatynski, Oxid. Met. 1979, 13, 105-118.

[48] T. Y. Kosolapova, Carbides, Springer US, Boston, MA, 1995. 


\section{Table of Content Graphic}

Carbon supported nanoparticles of early transition metal carbides $\left(\mathrm{ZrC}, \mathrm{Nb}_{6} \mathrm{C}_{5}, \mathrm{Mo}_{2} \mathrm{C}, \mathrm{TaC}\right.$, $\mathrm{W}_{2} \mathrm{C}$, WC) and hydrides $\left(\mathrm{ZrH}_{2}, \mathrm{NbH}_{0.8}, \mathrm{HfH}_{1.7}, \mathrm{TaH}_{0.5}\right)$ were synthesized from metal chlorides and potassium graphite without need for extensive external heating.

\section{Solid-state metathesis}
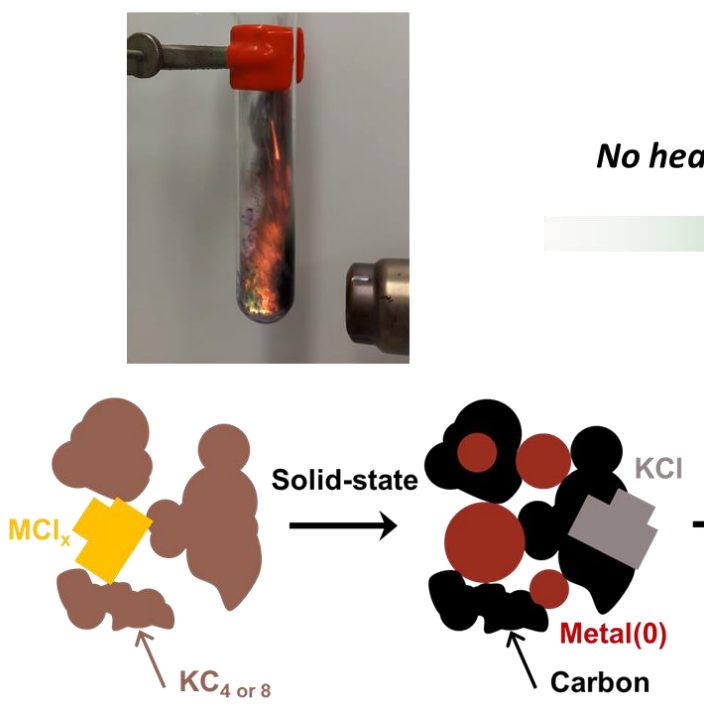

\section{Carbon supported nanos}

$\mathrm{NbC}, \mathrm{TaC}, \mathrm{Mo}_{2} \mathrm{C}, \mathrm{W}_{2} \mathrm{C}$
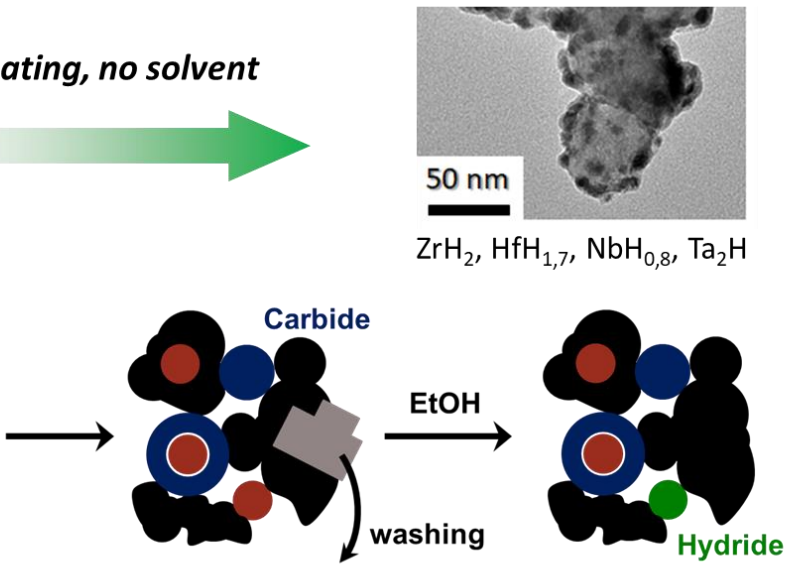